\title{
THE DESIGN OF A WIDEBAND AND WIDEBEAM PISTON TRANSDUCER IN A FINITE CLOSED CIRCULAR BAFFLE
}

\author{
A THESIS \\ SUBMITTED TO THE DEPARTMENT OF ELECTRICAL AND \\ ELECTRONICS ENGINEERING \\ AND THE INSTITUTE OF ENGINEERING AND SCIENCES \\ OF BILKENT UNIVERSITY \\ IN PARTIAL FULLFILMENT OF THE REQUIREMENTS \\ FOR THE DEGREE OF \\ MASTER OF SCIENCE
}

By

Zekeriyya Şahin

September 2008 
I certify that I have read this thesis and that in my opinion it is fully adequate, in scope and in quality, as a thesis for the degree of Master of Science.

Prof. Dr. Hayrettin Köymen (Supervisor)

I certify that $\mathrm{I}$ have read this thesis and that in my opinion it is fully adequate, in scope and in quality, as a thesis for the degree of Master of Science.

Prof. Dr. Ayhan Altıntaş

I certify that I have read this thesis and that in my opinion it is fully adequate, in scope and in quality, as a thesis for the degree of Master of Science.

Prof. Dr. Cevdet Aykanat

Approved for the Institute of Engineering and Sciences:

Prof. Dr. Mehmet B. Baray

Director of Institute of Engineering and Sciences 


\title{
ABSTRACT \\ THE DESIGN OF A WIDEBAND AND WIDEBEAM PISTON TRANSDUCER IN A FINITE CLOSED CIRCULAR BAFFLE
}

\author{
Zekeriyya Şahin \\ M.S. in Electrical and Electronics Engineering \\ Supervisor: Prof. Dr. Hayrettin Köymen
}

September 2008

The design of a high power piezoelectric underwater transducer operating at frequency range $42 \mathrm{kHz}-78 \mathrm{kHz}$ with acoustic power capability in excess of 250W is described. The transducer consists of two back-to-back elements. Each element is formed by stacked PZT-4 ceramic rings, a matching and a steel backing layer, and placed in a finite rigid circular baffle. We investigate the dependence of bandwidth and beamwidth to the combination of piston and baffle radii, a and $\mathrm{b}$, respectively. With $\mathrm{ka}$ of 2.45 ( $\mathrm{k}$ is the wave number) at resonance and a b/a ratio of 2 , the transducer resonates at $60 \mathrm{kHz}$ with $60 \%$ bandwidth and has a beamwidth of $60^{\circ}$ at each half space. We show that when two transducers are placed at right angles spatially and driven in parallel, we can obtain an omnidirectional beam pattern in the lower frequency band. The beam pattern exhibits two dips in each quadrant at the higher end of the frequency band, which are within $8 \mathrm{~dB}$. We also investigate power handling capability of the transducer from thermal point of view using finite element analysis. The input impedance measurements agree well with the numerical results within the pass band.

Keywords: Underwater acoustic transducer, finite baffle, wideband, wide beamwidth, high power 


\title{
ÖZET \\ DAİRESEL SONLU ENGEL ÜZERINDE GENIŞ BANT GENIŞ HÜZME AÇIKLIKLI PİSTON TIPİ AKUSTIKK DÖNÜŞTÜRÜCÜ TASARIMI
}

\author{
Zekeriyya Şahin \\ Elektrik ve Elektronik Mühendisliği Bölümü Yüksek Lisans \\ Tez Yöneticisi: Prof. Dr. Hayrettin Köymen \\ Eylül 2008
}

Dairesel sonlu engel üzerinde $42 \mathrm{kHz}-78 \mathrm{kHz}$ bandında, geniş hüzme açıklıklı, akustik güç kapasitesi 250W üzerinde olan piston tipi dönüştürücü tasarımı anlatılmıştır. Dönüştürücü, sırt sırta yerleştirilmiş iki elemandan oluşmaktadır. Her bir eleman, PZT-4 halkalar, uyumlama ve çelik arka katmanların sonlu dairesel engel üzerinde yığılmasıyla oluşturulmuştur. Bant genişliği ve hüzme açıklığının piston ve engel yarıçapına, sırasıyla a ve b, bağlı olarak gösterdiği değişim incelenmiş ve rapor edilmiştir. Dönüştürücünün rezonans frekansı $60 \mathrm{kHz}$ olup, $\mathrm{ka}=2.45$ ( $\mathrm{k}$ : dalga sayısı) ve $\mathrm{b} / \mathrm{a}=2$ için $\% 60$ bant genişliği ve yatay eksende her bir yarım düzlemde $60^{\circ}$ huzme açıklığı elde edilmiştir. İki tane dönüştürücü uzaysal olarak doğru bir açıyla yerleştirilip paralel olarak sürüldüğünde, alçak frekans bandında yatay eksende tümyönlü bir 1şınım örüntüsü elde edilebileceği gösterilmiştir. Işınım örüntüsü, frekans bandının üst kısmında her bir çeyrek düzlemde iki adet $8 \mathrm{~dB}$ 'den daha küçük bir çukur göstermiştir. Dönüştürücünün ısısl açıdan güç kapasitesi de sonlu eleman modeli ile analiz edilmiştir. Üretilen dönüştürücünün giriş empedansı geçiş bandında ölçülerek teorik sonuçlarla örtüştüğü gösterilmiştir.

Anahtar kelimeler: Sualtı akustik dönüştürücü, geniş bant, geniş 1şınım örüntüsü, sonlu engel, yüksek güç 


\section{Acknowledgements}

I would like to express my gratitude to my supervisor Prof. Dr. Hayrettin Koymen for his invaluable supervision and guidance of the thesis. I would also like to express my special thanks to the jury members Prof. Dr. Ayhan Altıntaş and Prof. Dr. Cevdet Aykanat for evaluating my thesis.

I am grateful to my friends Aykut and Sacit for their valuable help in ANSYS. I would also like to express my thanks to my parents and my friends for their endless support throughout my life.

Finally, special thanks to the TUBITAK for its' valuable financial support. 


\section{Table of Contents}

1. INTRODUCTION

1.1 HISTORY OF UNDERWATER ACOUSTICS ......................................................... 2

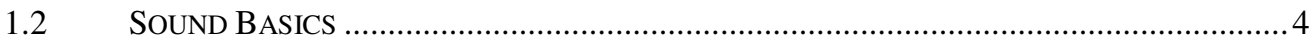

1.2.1 ACOUSTIC WAVES IN HoMOGENOUS MEDIUM ................................................... 4

1.2.2 BASIC DEFINITIONS AND UNITS............................................................... 6

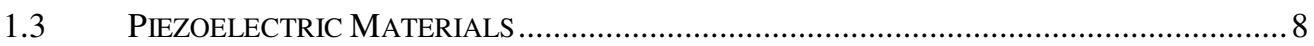

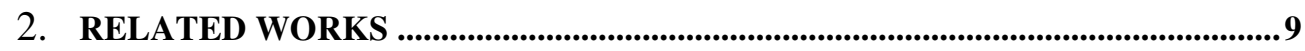

2.1 OVERVIEW OF THE TRANSDUCERS................................................................

2.2 RELATED WORKS ON SANDWICH TYPE TRANSDUCERS ......................................... 10

3. OPTIMIZATION OF TRANSDUCER DIMENSIONS FOR

OMNIDIRECTIONAL RADIATION PATTERN IN X-Y PLANE ..........................15

3.1 DERIVATION OF THE RADIATION IMPEDANCE AND RADIATION PATTERN OF A DISC IN A FINITE CLOSED CIRCULAR B AFFLE ............................................................................. 16 3.2 COMPARISON OF THE RESULTS FOR RADIATION IMPEDANCE AND RADIATION PATTERN OF A DISC IN A FINITE CLOSED CIRCULAR BAFFLE ................................................................. 22 3.3 DESIGN OF A NEW GEOMETRY USING Four PISTONS FOR OMNIDIRECTIONAL RADIATION

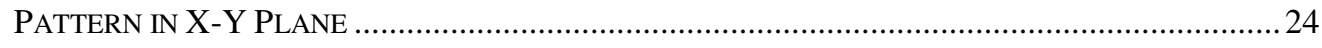

4. DESIGN OF A BACK-TO-BACK TRANSDUCER .........................................31

4.1 DESIGN OF A BACK-TO-BACK TRANSDUCER BY USING ELECTROMECHANICAL EQUIVALENT

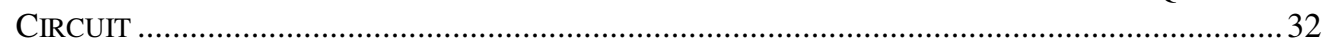

4.2 FINITE ELEMENT MODEL (FEM) OF THE BACK-TO-BACK TRANSDUCER ........................... 37

4.3 THERMAL ANALYSIS OF THE BACK-TO-BACK TRANSDUCER WITH FINITE ELEMENT MODEL

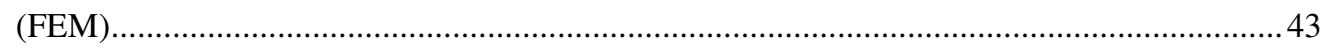

4.4 CAVITATION LIMIT ANALYSIS OF THE BACK-TO-BACK TRANSDUCER ................................50

4.5 AdMitTANCE MEASUREMENT OF THE BACK-TO-BACK TRANSDUCER ............................53

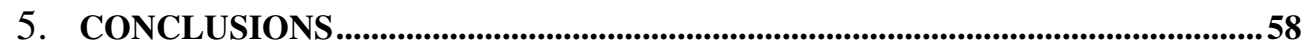

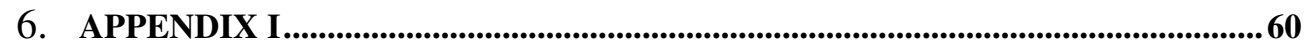

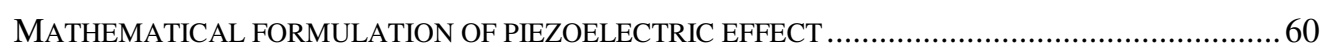

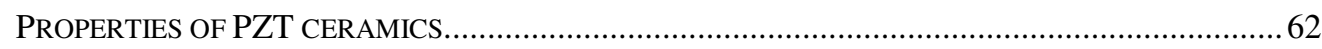

PIEZOELECTRIC COEFFICIENT MATRICES FOR THICKNESS MODE TRANSDUCER.......................63

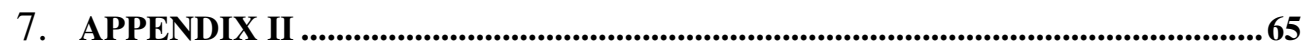

CALCUlation OF POWER SERIES COEFFICIENTS OF A DISC …............................................... 65

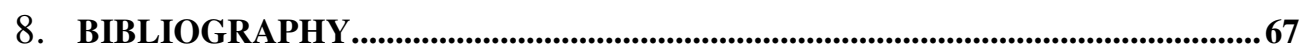




\section{List of Figures}

Figure 1. Three port equivalent model of transducer ....................................... 12

Figure 2. Electromechanical equivalent circuit of transducer......................... 12

Figure 3. Normalized directivity far field directivity function of a disc in a finite closed circular baffle with $b=2 a$

Figure 4. Normalized far field directivity function of a disc in a finite closed circular baffle with $k a=\frac{\pi}{2}$

Figure 5. Four radiating pistons placed spatially symmetric around the origin. 25

Figure 6. Normalized directivity function of a two back-to-back transducer in a finite baffle with $b=a, b=1.5 a, b=2 a, b=2.5 a$.

Figure 7. Normalized directivity function of a two back-to-back transducer in a finite baffle with $b=3 a$ and $b=8 a$

Figure 8. Normalized directivity function of a two back-to-back transducer in a finite baffle with $a=5 \mathrm{~mm}, a=9 \mathrm{~mm}, a=15 \mathrm{~mm}$ and $a=20 \mathrm{~mm}$.

Figure 9. Normalized directivity function of a two back-to-back transducer in a finite baffle with $\mathrm{r}=15 \mathrm{~mm}, \mathrm{r}=25 \mathrm{~mm}, \mathrm{r}=35 \mathrm{~mm}$ and $\mathrm{r}=45 \mathrm{~mm}$................. 28

Figure 10. Normalized vertical directivity function of a two back-to-back transducer in a finite baffle with $r=25 \mathrm{~mm}, b=2 a$ and $a=9 \mathrm{~mm}$.

Figure 11. Normalized directivity function of a back-to-back transducer in an infinite baffle and a finite baffle with $b=2 a \mathrm{a}=9 \mathrm{~mm}$ and $\mathrm{r}=25 \mathrm{~mm} \ldots \ldots \ldots \ldots . . .30$

Figure 12. Side view of a back-to-back transducer ....................................... 32

Figure 13. Electromechanical equivalent circuit of a back-to-back transducer . 33

Figure 14. Conductance-Susceptance seen from the electrical terminals obtained from equivalent circuit analysis

Figure 15. Power gain from one piston of a back-to-back transducer to the electrical terminals

Figure 16. Transmitting voltage response of each piston of a back-to-back transducer .....

Figure 17. Source pressure level of each piston of a back-to-back transducer .. 37

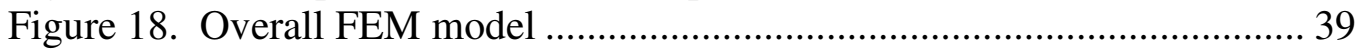

Figure 19. FEM of the back-to-back transducer.............................................. 39

Figure 20. Conductance seen from the electrical terminals obtained from FEM analysis.

Figure 21. Susceptance seen from the electrical terminals obtained from FEM analysis

Figure 22. Transmitting voltage response of one piston of a back-to-back

transducer obtained from FEM analysis.

Figure 23. Source pressure level of one piston of a back-to-back transducer .... 42

Figure 24 FEM model of back-to-back transducer with baffle ....................... 44

Figure 25. In-air steady state temperature distribution of back-to-back transducer 
Figure 26. In-air transient temperature response of the node at the inner surface of PZT.

Figure 27. In-water steady state temperature distribution of back-to-back

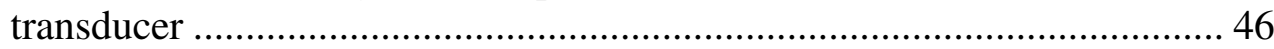

Figure 28. In-water Transient temperature response of the node at the inner surface of PZT

Figure 29. In-water steady state temperature distribution of back-to-back transducer with epoxy coating

Figure 30. In-water steady state temperature distribution of back-to-back transducer with polyurethane coating.

Figure 31. In-water steady state temperature distribution of back-to-back transducer with polyurethane filling and coating ................................... 49

Figure 32. Near-Field cavitation parameter.................................................... 51

Figure 33. Cavitation limited intensity for different frequencies ..................... 52

Figure 34. Cavitation limited acoustic power from one piston with respect to

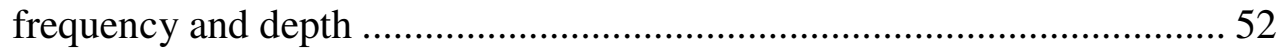

Figure 35. Constructed back-to-back transducer with plastic baffle................. 54

Figure 36. Water tank with dimensions $2 \mathrm{mX} 2 \mathrm{~m}$ and $1.5 \mathrm{~m}$ deep................... 54

Figure 37. Block diagram of the setup for admittance measurement................ 55

Figure 38. Control interface for the admittance measurement ......................... 56

Figure 39. Conductance-Susceptance obtained from measurement.................. 56

Figure 40. Comparison of the conductance from FEM analysis and measured data.

Figure 41. Comparison of the susceptance from FEM analysis and measured

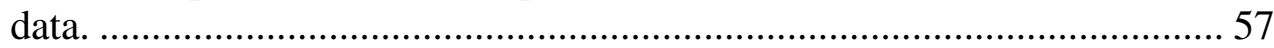

Figure 42. Comparison of dielectric tangent loss for PZT-4 and PZT-8 [7]..... 63 


\section{List of Tables}

Table 1 Analogous electrical and mechanical parameters. ................................ 6

Table 2. Properties of common PZT types...................................................... 62 


\section{Chapter 1}

\section{Introduction}

Electroacoustic transducers are the basic elements for all underwater systems which convert electrical waves to acoustic waves. Since the absorption of electromagnetic waves in the water is very high, almost all underwater applications depend on acoustic waves.

Transducers may vary both in size and shapes depending on the application requirements such as source pressure level, radiation pattern and frequency. In this work, we investigate two major subjects; design of a broadband high power piston transducer and optimization of the transducer dimensions to obtain omnidirectional beam pattern in the desired frequency band. Transducer dimensions are tried to be optimized to achieve both high bandwidth and high beamwidth as radiation characteristics and operating band both depend on the transducer dimensions.

In the first chapter, after giving some historical background on acoustics, we briefly explain the analogy between electromagnetic and acoustic waves. Then, we define some basic concepts and units that are useful for understanding the rest of the work. Additionally, general piezoelectric materials used for the transducer design are described and the advantages of the chosen ceramic material for the design of the transducer are explained.

In the second chapter, we discuss the related works on underwater transducers. Firstly, we make an overview of the transducer types that are commonly used in underwater acoustics and evaluate their properties. Then, we analyze the previous literature on the sandwich type transducers. 
Third chapter concentrates on the design of an omnidirectional beam pattern in $\mathrm{X}-\mathrm{Y}$ plane. In the first section, we calculate radiation pattern of a disc in a finite closed circular baffle. The results are then compared to that have been recently derived by Mellow and Kärkkäinen in the second section [1]. Finally, we describe a new geometry using four radiating pistons to obtain an omnidirectional beam pattern.

In the last chapter, we propose a design of a broadband bi-directional piston transducer using two conventional piston type transducers in a back-to-back configuration. Both electromechanical equivalent circuit and finite element model (FEM) analysis of the transducer are described. Thermal characteristics of the back-to-back transducer and the problem of cavitation are also investigated. Input admittance measurement of the constructed back-to-back transducer in the acoustic water tank is shown as well.

\subsection{History of Underwater Acoustics}

At the end of the fifteenth century Leonardo da Vinci wrote: "If you cause your ship to stop, and place the head of a long tube in the water and place the outer extremity to your ear, you will hear ships at a great distance from you."

His remarkable words laid the foundation of underwater acoustics. He pointed out many crucial points in underwater acoustics; moving ships generate sounds that propagate to a large distance; self noise should be handled in order to detect acoustic signals, and one has to design a receiver to increase detection probability.

After Leonardo da Vinci, many people worked on the sound. First mathematical approach to the theory of sound was introduced by Newton [2]. 
The speed of sound in water was first measured by Daniel Colladon and Charles Sturm in 1826 [2]. Few decades later, Alexander G. Bell was the first who made conversion between acoustical-electrical-acoustical signals in 1876 [3]. Next year, Lord Rayleigh published his famous book Theory of Sound which is one of the monumental works in acoustics since it not only gives the basics of acoustic theory, but also covers the generation, propagation and reception of sound and elastic behavior of solids, liquids and gases [2]. Discovery of piezoelectricity in quartz crystals by Jacques and Pierre Curie in 1880 was certainly a milestone for underwater acoustics as materials with such properties are still being used in most of the underwater acoustic transducers [3]. Following to Curie brothers, French scientist Langevin introduced the detection of submarine with an active system where he was able to drive a quartz transducer at $38 \mathrm{kHz}$ in 1917 [2].

Around the World War II, as the submarines become a serious threat, necessities for SONARs (SOund NAvigation and Ranging) and high performance transducers for the security of own vessels become inevitable. Therefore, scientist tried to find new materials which have better performance than quartz for the design of transducers. Hippel discovered piezoelectricity in polarized barium titanate and in lead zirconate titanate (PZT) ceramics in 1944 and 1954, respectively [3]. These materials have stronger piezoelectric properties than quartz and discovery of them initiated the production of modern piezoelectric transducers that are still being used in most of the transducers.

Today, although ceramics are still used for the design of underwater transducers, new materials are being developed such as lead magnesium niobate $(\mathrm{PMN})$, piezo-composite materials and single crystals. Parallel to improvements in transducer technology, new and high-speed signal processing units result in a highly intelligent, fast and long range acoustic devices such as modern SONARs and acoustic torpedo heads. 
Moreover, scientists have also directed their researches towards new non-military applications at the end of twentieth century such as investigation of ocean environment and sea animals, bathymetry and analysis of seabed for oil reservoirs.

\subsection{Sound Basics}

The theory of sound wave is very similar to the theory of electromagnetic wave. In fact, the derivation of the equations is exactly the same with analogous quantities.

\subsubsection{Acoustic Waves in Homogenous Medium}

Assume a small volume element of length $d x$ and of unit area. An applied force change the volume $d x$ to $d x+d \Delta_{x}$ where $d \Delta_{x}=\frac{\partial \Delta_{x}}{\partial x} d x$. Strain is defined as the ratio of change in the volume to the initial volume which is equal to $\frac{\partial \Delta_{x}}{\partial x}$. Then, the wave equation in an ideal fluid can be derived from Hooke's Law and Newton's Second Law. Hook's law states that the ratio of stress to strain is constant called bulk modulus of elasticity [4]:

$$
P(x)=-B \frac{\partial \Delta_{x}}{\partial x}
$$

In the above equation $P$ is the static pressure, $B$ is the bulk modulus. Using Newton's Second Law, net pressure equals to mass times the acceleration

$$
\frac{\partial P(x, t)}{\partial x}=-\rho \frac{\partial v(x, t)}{\partial t}
$$


where $\rho$ is the density of the medium, $v$ is the particle velocity, $\rho d x$ is the mass.

In case of a time varying pressure, strain is also time-varying. Taking the derivative of Eq. 1 with respect to time gives,

$$
-B \frac{\partial v(x, t)}{\partial x}=\frac{\partial P(x, t)}{\partial t}
$$

Eq. 1.2 and 1.3 are analogues to electrical lossless transmission line. Taking the derivative of Eq.1.2 with respect to $\mathrm{x}$ and Eq. 1.3 with respect to time, we obtain;

$$
\begin{aligned}
& \frac{\partial^{2} P(x, t)}{\partial^{2} x}=-\rho \frac{\partial}{\partial x}\left(\frac{\partial v(x, t)}{\partial t}\right) \\
& \frac{\partial^{2} P(x, t)}{\partial^{2} t}=-B \frac{\partial}{\partial x}\left(\frac{\partial v(x, t)}{\partial t}\right)
\end{aligned}
$$

Equating right hand sides of the Eq. 1.4 and 1.5 gives;

$$
\frac{\partial^{2} P(x, t)}{\partial^{2} x}=\frac{\rho}{B} \frac{\partial^{2} P(x, t)}{\partial^{2} t}
$$

which is a well known differential equation that has solutions of the form;

$$
P(x, t)=A e^{j(w t-k x)}+C e^{j(w t+k x)}
$$

note from Eq. 1.6 that, wave travels with a speed $c=\sqrt{\frac{B}{\rho}}$.

Using the analogy with the electrical system and the property $c=\sqrt{\frac{B}{\rho}}$ specific acoustic impedance can be defined as the ratio of pressure to particle speed given as; 


$$
Z_{0}=\sqrt{B \rho}=\rho c
$$

The analogous electrical and mechanical parameters are shown in Table $1[2]$.

\begin{tabular}{|c|c|c|c|}
\hline \multicolumn{2}{|c|}{ Electrical Parameter } & \multicolumn{2}{c|}{ Mechanical Parameter } \\
\hline Voltage & $v$ & Pressure & $P$ \\
\hline Current & $i$ & Particle Speed & $v$ \\
\hline Inductance/Unit Length & $L$ & Density & $\rho$ \\
\hline Capacitance/Unit Length & $C$ & Inverse Bulk Modulus of & $\frac{1}{B}$ \\
\hline
\end{tabular}

Table 1 Analogous electrical and mechanical parameters.

\subsubsection{Basic Definitions and Units}

This section presents a brief overview of the basic definitions and units of underwater acoustics to understand the rest of the work. Although some important literature, especially before 1970's, uses earlier systems of units, CGS, we consider the more general units in MKS system [2].

Pressure: In a plane wave of sound, the pressure $P$ is related to the velocity of the particle $v$ by;

$$
P=\rho c v
$$

where $\rho$ is the density and $c$ is the sound speed in the medium. 
Specific Acoustic Impedance: The term $\rho c$ in Eq. 1.9 is called specific acoustic impedance of the medium assuming that proportionality factor between pressure and velocity is complex. In fact, this result is analogous to electrical impedance since velocity is the analog of current and pressure is the analog of voltage. Sound speed and specific acoustic impedance of water are, $1500 \mathrm{~m} / \mathrm{s}$ and $1.5 x^{6} 10 \frac{\mathrm{kg}}{\mathrm{m}^{2} \mathrm{~s}}$, respectively. Sometimes $\frac{\mathrm{kg}}{\mathrm{m}^{2} \mathrm{~s}}$ defined as Rayl and therefore specific impedance of water defined as 1.5Mrayl.

Intensity: For a plane wave, the instantaneous sound intensity is defined as the ratio of the instantaneous pressure $(\mathrm{Pa})$ to specific acoustic impedance:

$$
I=\frac{P^{2}}{\rho c}
$$

Source Pressure Level: Source level describes the strength of a source in terms of intensity produced at a reference distance. In MKS system reference distance is $1 \mathrm{~m}$. The source level of a compact source of $P$ watts is given by:

$$
\text { SPL re } 1 \mu P a @ 1 \mathrm{~m}=170.77 \mathrm{~dB}+10 \log P
$$

Although we are dealing with the sound intensity it's easier to measure sound pressure than sound intensity. Hence, generally pressure is measured and from that intensity is inferred. Within the same medium, sound intensity or power is proportional to the average of the squared pressure. Thus, in $\mathrm{dB}$ scale, source intensity level (SIL) and source pressure level (SPL) is the same thing.

Transmitting Voltage Response (TVR): Transmitting voltage response is defined as the pressure generated at $1 \mathrm{~m}$ range by the source per $1 \mathrm{~V}$ of input voltage as a function of frequency. 


\subsection{Piezoelectric Materials}

Piezoelectricity is the general term to describe the property exhibited by some types of crystals that become electrically polarized when stress is applied to them. Curie brothers, who discovered the piezoelectricity in 1880 , observed positive and negative charges appeared on the several parts of the crystal surface when they applied stress from different directions [3]. This effect, converting mechanical energy to electrical energy, was later called the direct piezoelectric effect. Piezoelectric materials also exhibit the converse piezoelectric effect, converting electrical energy to mechanical energy. A summary of mathematical formulation of the piezoelectric effect and relationship between mechanical and electrical parameters are given in Appendix I [3,5].

Common materials that have piezoelectric properties are quartz, barium titanate, lead titanate and lead zirconate titanate (PZT). Because of having high coupling factors, high piezoelectric dielectric constants over extended temperature ranges and stress amplitudes, PZT ceramics are the most extensively used material for electro-mechanical transducers [6]. Since its' properties can be optimized, different types of PZT ceramics are being used in underwater transducer design. Appendix I gives basic properties of common types of PZT ceramics [7].

In this work, for the design of the back-to-back transducer we choose to use PZT-4 ceramics for various reasons. PZT-4 has a high resistance to depolarization and low loss tangent under high electric drive. Its high resistance to depolarization under mechanical stress makes it suitable for use in deep water. Although PZT-8 has smaller tangent loss, given in Fig. 42, its coupling coefficient is also lower than PZT-4 [7]. Note that PZT-2, PZT-5A and PZT-5H are not suitable for high power applications due to high dielectric loss. 


\section{Chapter 2}

\section{Related Works}

Throughout this chapter, we briefly overview transducer types and evaluate some works on the field of piston type transducers. In section 2.1, we summarize various transducer types that are commonly used for underwater applications, compare them according to their applications and discuss the general design criteria. We focus on the projectors rather than hydrophones since projectors are larger and more complex due to the need of generating high acoustic power. Section 2.2 provides an insight into the design considerations of piston type transducers by analyzing previous literature.

\subsection{Overview of the Transducers}

The design of high power underwater projectors is important for underwater applications. Transducers may have various sizes and shapes depending on the most important application requirements such as operating frequency band, output power and radiation pattern. Cylinders, spheres, piston (tonpilz, sandwich) and flextensional transducers are some of the transducers that are typically used in underwater acoustics today.

Operating frequency band is the most important criterion that determines the type and size of the transducer. At low frequencies, transducers which have low resonant frequencies with manageable size such as flextensional transducers are most suitable. In the mid frequency band, Tonpilz type piston transducer are commonly used. If the transducer is to operate at high frequencies, lumped elements have to be small and the wave nature of the transducer become more 
influential. Therefore, sandwich type piston transducers are usually preferred at high frequencies, particularly above $10 \mathrm{kHz}$ [3].

High efficiency is also important for any transducer that depends mostly on active materials used for the design. If broadband operation is required it is difficult to obtain high efficiency which has led to the development of new materials such as Terfenol-D, PMN and single crystal PMN-PT. Single crystals, particularly, have extremely high coupling coefficients [3].

Radiation characteristic of transducers has a strong impact on the application where they are to be used. Typically, transducers that are small compared to wavelength, such as flextensional transducers, have nearly omnidirectional radiation pattern. Spherical transducers are truly 3-D omnidirectional for all frequencies, while cylindrical transducers are omnidirectional only in a plane perpendicular to axis. On the other hand, piston transducers are unidirectional which enables them the most suitable one for applications that require highly directional arrays.

Another design criterion that we discuss lastly is the output power. High output power is of paramount importance for any projector. Sandwich transducers can endure high tensile strength by bolting ceramic elements with backing and matching layers under compressive stress, therefore they can be driven at high power levels without damaging transducer. The most typical problem that arises when transducers are driven at high levels is heating.

\subsection{Related Works on Sandwich Type Transducers}

Piston type transducers are the most common transducer in underwater acoustics. Since they have directional beam pattern with directionality depends on the size compared to wavelength, they are the most appropriate transducers for arrays to obtain high intensity and highly directional beams. Two types of 
piston transducers are tonpilz and sandwich type transmission line transducers. While tonpilz transducers operate from $1 \mathrm{kHz}$ to $50 \mathrm{kHz}$, sandwich transducers cover the frequency range from $10 \mathrm{kHz}$ to few $\mathrm{MHz}$ [3]. This section covers the related works that have been done for the sandwich type transducers in terms of design considerations.

Electromechanical equivalent circuit of thickness mode transducer was first defined by Mason [8]. He modeled the transducer as a three port system and assumed that the transducer is driven in thickness mode with parallel electrodes on both sides as shown in Fig. 1. The two faces of the transducer represent the mechanical ports. After that, he defined the electromechanical equivalent circuit of transducer as given in Fig. 2 where $\Phi$ is the electromechanical transformation ratio, $C_{0}$ is the clamped capacitance, $t$ is the thickness and $Z_{c}$ is the mechanical impedance of the transducer with area $A$ and their expressions are;

$$
\begin{gathered}
\Phi=C_{0} h_{33} \\
C_{0}=\frac{A \varepsilon_{33}^{S}}{t} \\
Z_{c}=Z_{0} A \\
Z_{b}=-\frac{j Z_{c}}{\sin (k l)} \\
Z_{a}=j Z_{c} \tan \left(\frac{k l}{2}\right)
\end{gathered}
$$

In above equations, $Z_{0}$ is the characteristic impedance of the transducer given in section 1.2.2, $l$ is the thickness, $k$ is the wave number, $\varepsilon_{33}^{S}$ is the clamped dielectric constant and $h_{33}$ is the plate stiffness. 


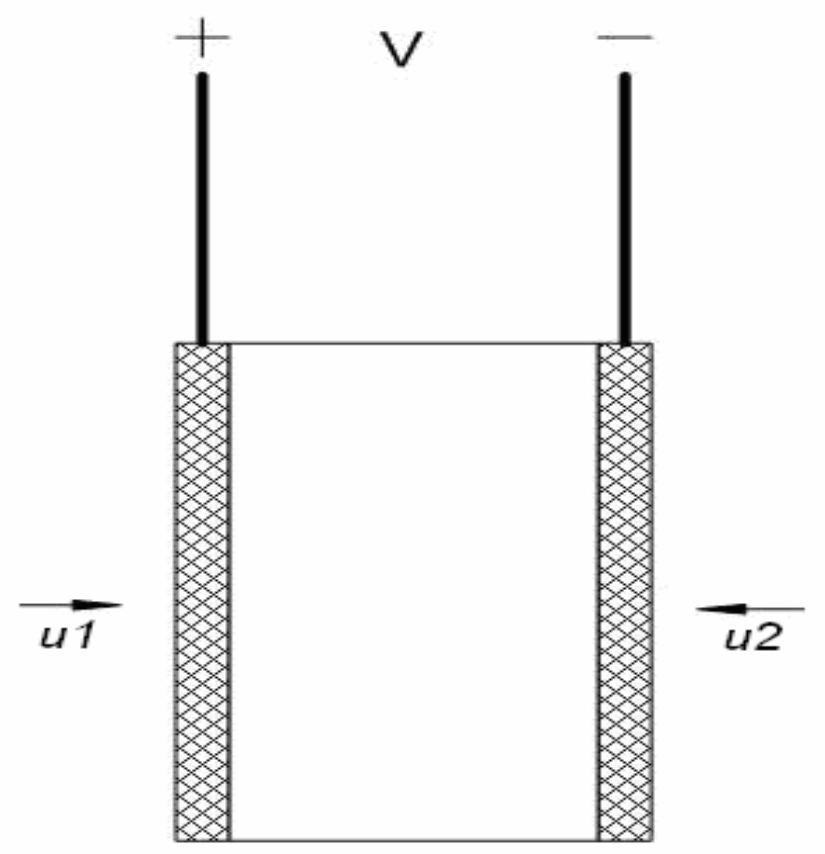

Figure 1. Three port equivalent model of transducer

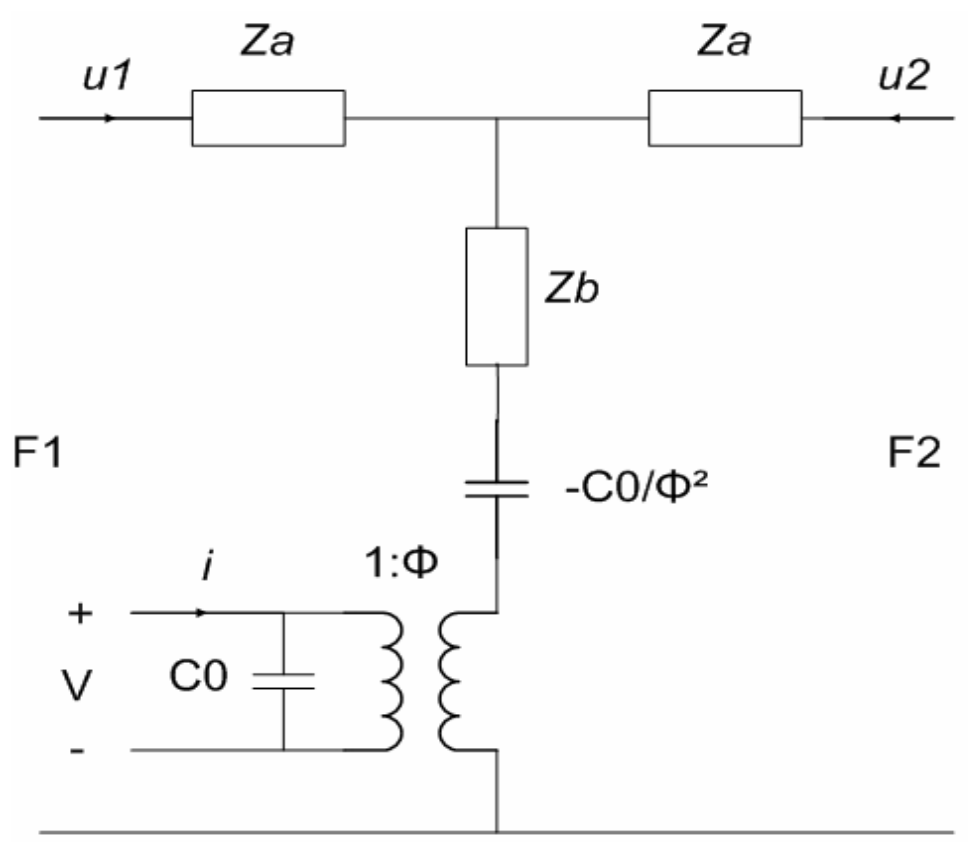

Figure 2. Electromechanical equivalent circuit of transducer.

Electromechanical equivalent circuit, presented by Mason, had been the best way of designing sandwich transducers until the Finite Element Methods (FEM) 
aroused. Even today, it obviously provides a detailed insight into the design of sandwich type transducers. In fact, if the sound speeds of the materials are determined correctly for the given ceramic geometry, Mason Equivalent Model yields very close results as FEM does. An obvious difference between them is; only the 33 mode vibration is taken into account in the equivalent circuit model. Moreover, equivalent circuit model also assumes ideal conditions and none of the effects such that reflections, radial and shear mode vibrations are included.

In sandwich transducers, broadband operation is of paramount importance. Kossoff improved the Mason equivalent model and analyzed the effects of backing and matching on the performance of the transducers [9]. Because of the large impedance mismatch between transducer and water load, bandwidth of the transducer is very small. He first increased the bandwidth by adding a high impedance backing layer so that large portion of the acoustical power transmitted into water. He then added quarter wave matching layer between the transducer and water load to obtain very wide bandwidth.

Radiation characteristics of pistons have been addressed so extensively in the literature since it has been a challenging problem to derive exact radiation solution for a piston in a finite closed circular baffle. Most common assumption in determining the radiation pattern and impedance is that the transducer is in an infinite baffle. However, the assumption of infinite baffle is not appropriate for applications which do not contain any baffle. King proposed a method to calculate radiation characteristics of a disk in an infinite baffle where he used Green's function in cylindrical coordinates [10]. Several years later, the directivity and radiation impedance of a rigid disc in a finite circular open baffle for low values of $k a$ where $k$ is the wave number and $a$ is the radius of the disc was calculated by Nimura and Watanabe [11] and Levine and Schwinger investigated the radiation of sound from an unflanged circular pipe [12]. Mellow and Kärkkäinen has recently derived the radiation characteristics of a rigid disc in a finite open baffle. They have formulated the calculation of power series 
coefficients of a rigid disc in a finite open baffle as given in Appendix II According to their result, they were able to calculate power series coefficients for $\mathrm{b}=8 \mathrm{a}$ with $\mathrm{M}=200, \mathrm{~N}=40$ and 140 digits of precision, where $\mathrm{M}$ is the order of Bouwkamp and Streng functions, $\mathrm{N}$ is the order of Bessel series, $\mathrm{b}$ and a are the radii of baffle and disc, respectively. They have also shown that sound radiation characteristics of a disc in a finite closed circular baffle can be obtained by combining the radiation fields of a disc in a finite open baffle and that of a disk in an infinite baffle [1]. Their results also include the exact equations for the radiation impedance of a disc in a finite closed circular baffle which are also given in Appendix II.

In the next chapter, we improve Mellow and Kärkkäinen's results and derive a recursive method for the calculation of radiation impedance and radiation pattern of a piston in a finite closed circular baffle. Then, we design a new geometry using four radiating pistons and try to obtain omnidirectional radiation pattern in $\mathrm{X}-\mathrm{Y}$ plane. 


\section{Chapter 3}

\section{Optimization of Transducer Dimensions for Omnidirectional Radiation Pattern in X-Y Plane}

In Appendix II, radiation pattern and radiation impedance equations of a disk in a finite closed circular baffle are given for a baffle thickness of one quarter of piston radius. In case of a baffle which has larger thickness, we expect to see a second reflection when the wave reaches the edge of the rear surface, but this would produce weaker interference patterns because some of the wave has already been reflected at the edge of the front surface. In case of the closed back disk with no baffle, the beam pattern is the same as that of a piston at the end of an infinite tube derived by Levine and Schwinger which proves our assumption [12]. Therefore, same model can be used for baffle thickness larger than one quarter of the piston diameter.

In this chapter, we first simplify the equations derived by Mellow and Kärkkäinen in order to reduce computation time for the calculation of the exact radiation pattern of a disc. Following to comparison of our results with the ones they have obtained, we search for a new geometry using radiating pistons to achieve an omnidirectional beam pattern in X-Y plane. 


\subsection{Derivation of the Radiation Impedance and Radiation Pattern of a Disc in a Finite Closed Circular Baffle}

Power series coefficients of a disc are obtained from Eq. II.4 given in Appendix II. Bouwkamp function in Eq. II.1 can be written as;

$$
{ }^{B} B_{q}(k b)=A_{q}(k b) \sum_{r=0}^{M} a_{r}(m, q, k b)
$$

where

$$
A_{q}(k b)=\frac{\sqrt{\pi}(-1)^{q}}{(q !)^{2}}\left(\frac{k b}{2}\right)^{2 q+3}
$$

and

$$
a_{r}(m, q, k b)=\frac{(-1)^{r} \Gamma(m+5 / 2) \Gamma(q+r+1)}{r ! \Gamma(r+m+5 / 2) \Gamma(q+r+5 / 2)} \times\left(\frac{k b}{2}\right)^{2 r}
$$

Let us define

$$
K_{r}(m, q, k b)=\frac{a_{r+1}(m, q, k b)}{a_{r}(m, q, k b)}
$$

Using properties of Gamma function leads to the following expression for $K_{r}$ [13]:

$$
K_{r}(m, q, k b)=-\frac{(q+r+1)(k b)^{2}}{(r+1)[2(r+m)+5][2(q+r)+5]}
$$

Assuming $M$ is even and noting that;

$$
\sum_{r=0}^{M} a_{r}=a_{0}+\sum_{r=1}^{M / 2} a_{2 r}+\sum_{r=1}^{M / 2} a_{2 r-1}
$$

with the property;

$$
a_{2 r}+a_{2 r-1}=\left(1+K_{2 r-1}\right) a_{2 r-1}
$$


Eq. 3.6 becomes

$$
\sum_{r=0}^{M} a_{r}=a_{0}+\sum_{j=0}^{M / 2-1}\left(1+K_{2 j+1}\right) a_{2 j+1}
$$

The term $a_{2 j+1}$ in Eq. 3.8 can be written as;

$$
a_{2 j+1}=K_{2 j} a_{2 j}=K_{2 j} K_{2 j-1} a_{2 j-1}=a_{0} \prod_{i=0}^{2 j} K_{i}
$$

Then Eq. 3.8 becomes,

$$
\sum_{r=0}^{M} a_{r}=a_{0}\left[1+\sum_{j=0}^{M / 2-1}\left(1+K_{2 j+1}\right) \prod_{i=0}^{2 j} K_{i}\right]
$$

which led to the following recursive formula;

$$
\sum_{r=0}^{M} a_{r}=a_{0}\left[1+K_{0}\left[1+K_{1}\left[1+\left[\ldots+K_{M-2}\left[1+K_{M-1}\right]\right]\right]\right]\right]
$$

Using Eq. 3.5;

$$
K_{M-1}=\frac{-\left(1+\frac{q}{M}\right)}{(2 M)^{2}} \frac{(k b)^{2}}{\left(1+\frac{m}{M}+\frac{3}{2 M}\right)\left(1+\frac{q}{M}+\frac{3}{2 M}\right)}
$$

Taking the limit when $M \rightarrow \infty$;

$$
\lim _{M \rightarrow \infty} K_{M-1}=-\left(\frac{k b}{2 M}\right)^{2} \frac{1}{\left(1+\frac{m}{M}\right)}
$$




$$
=\left\{\begin{array}{lll}
-\left(\frac{k b}{2 M}\right)^{2} & \text { for } & m=q=0 \\
-\frac{1}{2}\left(\frac{k b}{2 M}\right)^{2} & \text { for } & m=q=M
\end{array}\right\}
$$

Therefore for a convergence we choose $2 M \gg k b$. Lastly, taking $A_{q}(k b) a_{0}$ term in Eq. 3.1 where $a_{0}$ comes from Eq. 3.11;

$$
A_{q}(k b) a_{0}(m, k ; k b)=\frac{(-1)^{q}}{(q !)} \frac{(k b)^{2 q+3}}{2^{2 q+3}} \frac{1}{1 \cdot 3 \cdot 5 \cdots(2 q+3)}
$$

Using the property;

$$
\frac{1}{1 \cdot 3 \cdot 5 \cdots(2 q+3)}=\frac{(q+1) ! 2^{q+1}}{(2 q+3) !}
$$

Eq. 3.15 becomes

$$
A_{q}(k b) a_{0}(m, k ; k b)=(-1)^{q}(q+1) \frac{(k b)^{2 q+3}}{(2 q+3) !}
$$

As a result, we can calculate Bouwkamp function recursively with the following formula.

$$
m^{B} q^{(k b)}=A_{q} a_{0}\left[1+K_{0}\left[1+K_{1}\left[1+\left[\ldots+K_{M-2}\left[1+K_{M-1}\right]\right]\right]\right]\right.
$$

We implement similar derivation on the Streng function. Since the term $\Gamma(r+q-m+1)$ goes to infinity for some values of $r, q$ and $m$, derivation is more complex than in case of the Bouwkamp function. Eq. II.2 in Appendix II can be written as;

$$
{ }_{m} S_{q}(k b)=D_{q m}(k b) \sum_{r=0}^{M} b_{r}(m, q, k b)
$$

where 


$$
D_{q m}(k b)=\frac{\sqrt{\pi}(-1)^{q+m}}{(q !)^{2}}\left(\frac{k b}{2}\right)^{2(q-m)}
$$

and

$$
b_{r}(m, q, k b)=\frac{(-1)^{r} \Gamma(m+5 / 2) \Gamma(r+q-m-1 / 2)}{r ! \Gamma(r-m-1 / 2) \Gamma(r+q-m+1)} \times\left(\frac{k b}{2}\right)^{2 r}
$$

In Eq 3.21, Streng function is zero for $r<m-q$ since;

$$
\frac{1}{\Gamma(r+q-m+1)}=\left\{\begin{array}{lll}
0 & \text { for } & r \leq m-q-1 \\
\neq 0 & \text { for } & r \geq m-q
\end{array}\right\}
$$

Then Streng function becomes;

$$
m^{S}(k b)=D_{q m}(k b) \sum_{r=m-q}^{M} b_{r}(m, q, k b) \text { for } m \geq q
$$

Let us define;

$$
\begin{gathered}
L_{r}(m, q, k b)=\frac{b_{r+1}(m, q, k b)}{b_{r}(m, q, k b)} \\
L_{r}(m, q, k b)=-\left(\frac{k b}{2}\right)^{2} \frac{(q+r-m-1 / 2)}{(r+1)(r+q-m+1)}
\end{gathered}
$$

such that using the results from Eq. 3.6 through Eq. 3.9 second term in Eq. 3.23 turns out to be

$$
r=m-q) b_{r}=b_{m-q}\left[1+\sum_{j=0}^{M / 2-1}\left(1+L_{2 j+1}\right) \prod_{i=0}^{2 j} L_{i}\right]
$$

where

$$
b_{m-q}=(-1)^{m-q}\left(\frac{k b}{2}\right)^{2(m-q)} \frac{\Gamma(m+5 / 2) \Gamma(-1 / 2)}{\Gamma(m-q+1) \Gamma(-q-1 / 2)}
$$


Lastly, we put Eq. 3.20 and 3.26 into Eq 3.23 to get recursive formula for Streng function as following;

$$
m S_{q}(k b)=D_{q m} b_{m-q}\left[1+L_{0}\left[1+L_{1}\left[1+\left[\ldots+L_{M-2}{ }^{\left.\left.\left.\left.\left[1+L_{M-1}\right]\right]\right]\right]\right]}\right.\right.\right.\right.
$$

Using Eq. 3.25;

$$
\begin{aligned}
L_{M-1} & =-\left(\frac{k b}{2}\right)^{2} \frac{(M+q-m-3 / 2)}{M(M+q-m)} \\
& =-\left(\frac{k b}{2}\right)^{2} \frac{\left(1-\frac{3 / 2}{M+q-m}\right)}{M}
\end{aligned}
$$

Taking the limit when $M \rightarrow \infty$;

$$
\begin{aligned}
\lim _{M \rightarrow \infty} L_{M-1} & =-\left(\frac{k b}{2}\right)^{2} \frac{\left(1-\frac{3 / 2}{M+q-m}\right)}{M} \\
& =\left\{-\frac{1}{M}\left(\frac{k b}{2}\right)^{2}\right\}
\end{aligned}
$$

Therefore for a convergence we choose $M \gg(k b)^{2}$. First term in Eq. 3.28 can be obtained by combining Eq.3.27 and Eq. 3.20

$$
D_{q m} b_{m-q}=\frac{\sqrt{\pi}}{(q !)^{2}} \frac{\Gamma(m+5 / 2) \Gamma(-1 / 2)}{\Gamma(m-q+1) \Gamma[-(q+1 / 2)]}
$$

Using the following properties of gamma function;

$$
\begin{aligned}
& \Gamma(-1 / 2)=\frac{\Gamma(1 / 2)}{-1 / 2}=-2 \Gamma(1 / 2) \\
& \Gamma(-q-1 / 2)=\frac{\Gamma(-q+1 / 2)}{-q-1 / 2}=\frac{\Gamma(-q+3 / 2)}{(-q-1 / 2)(-q+1 / 2)} \\
& =\frac{1}{-q-1 / 2} \cdot \frac{1}{-(q)+1 / 2} \cdot \frac{1}{-(q-1)+1 / 2} \cdots \frac{\Gamma(1 / 2)}{-1 / 2}
\end{aligned}
$$




$$
=\frac{1}{-q-1 / 2} \Gamma(1 / 2) \prod_{n=0}^{q-1} \frac{1}{(-q+n+1 / 2)}
$$

Following result is derived;

$$
\frac{\Gamma(-1 / 2)}{\Gamma(-q-1 / 2)}=2(q+1 / 2) \prod_{n=0}^{q-1}(-q+n+1 / 2)
$$

Next, we take the term $\Gamma(m+5 / 2)$ in Eq. 3.29. Using the property;

$$
\Gamma(n+1 / 2)=\frac{1 \cdot 3 \cdot 5 \ldots(2 n-1)}{2^{n}} \sqrt{\pi}
$$

$\Gamma(m+5 / 2)$ can be written as;

$$
\begin{aligned}
\Gamma(m+5 / 2) & =\frac{1 \cdot 3 \cdot 5 \cdots[2(m+2)-1]}{2^{m+2}} \sqrt{\pi} \\
& =\frac{(m+1) !}{2} \sqrt{\pi}=\Gamma(m+2)
\end{aligned}
$$

Then using Eq. 3.34 yields the following result;

$$
\begin{aligned}
\frac{\Gamma(m+5 / 2)}{\Gamma[m-(q-1)]} & =\frac{\sqrt{\pi}}{2} \frac{\Gamma(m+2)}{\Gamma[m-(q-1)]} \\
& =\frac{\sqrt{\pi}}{2} \prod_{n=0}^{q}(m-n+1)
\end{aligned}
$$

Finally, we combine Eq. 3.35 and Eq 3.38 and obtain the following formula;

$$
D_{q m} b_{m-q}=\frac{\pi}{(q !)^{2}} \prod_{n=0}^{q}(-q+n-1 / 2)(m-n+1)
$$

As a result, Streng function can be calculated using Eq. 3.39, 3.28 and 3.25.

In the next section, we compute the radiation pattern of a disc in a finite closed circular baffle and compare the results with the ones obtained by Mellow and Kärkkäinen [1]. 


\subsection{Comparison of the Results for Radiation Impedance and Radiation Pattern of a Disc in a Finite Closed Circular Baffle}

In order to verify our results with the ones obtained by Mellow and Kärkkäinen, we calculate and plot radiation pattern for a single radiating disc with a different baffle and piston radii. Normalized directivity far field directivity function of a disc in a finite closed circular baffle for various $k a$ values with $\mathrm{b}=2 \mathrm{a}, 20 \log _{10}\left(\frac{|D(\theta)|}{|D(0)|}\right)$, is plotted in Fig. 3 according to the Eq. II.5 in Appendix II where power series coefficients are derived using the results obtained in the previous section. Fig. 4 shows the normalized far field directivity function for different baffle sizes with $k a=\frac{\pi}{2}$. For all baffle sizes calculations are performed with $\mathrm{M}=50, \mathrm{~N}=10$ and 60 digits of precision and calculation time decreases significantly. Note that, the results are exactly the same as those obtained by Mellow and Kärkkäinen [1]. 


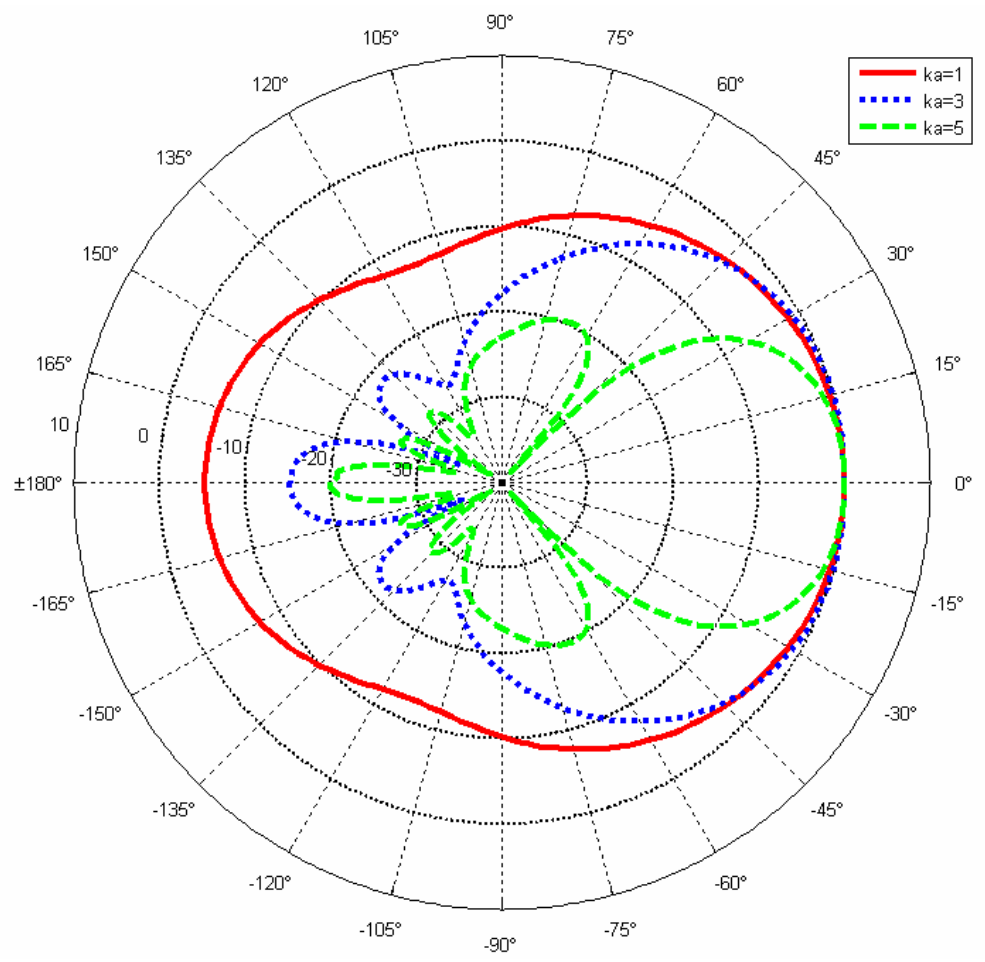

Figure 3. Normalized directivity far field directivity function of a disc in a finite closed circular baffle with $b=2 a$

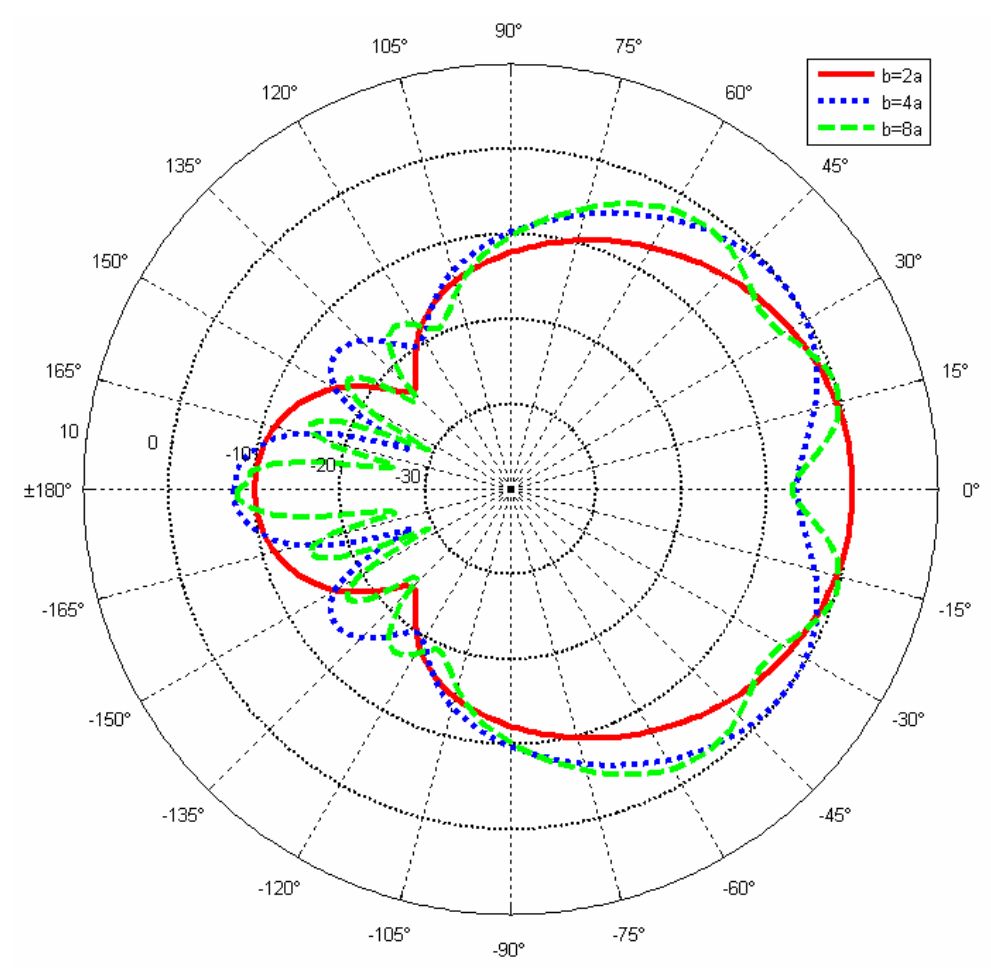

Figure 4. Normalized far field directivity function of a disc in a finite closed circular baffle with $k a=\frac{\pi}{2}$ 


\subsection{Design of a New Geometry Using Four Pistons for Omnidirectional Radiation Pattern in X-Y Plane}

Far-field pressure response of a circular piston, of radius a, in a finite baffle, of radius $b$, is given as;

$$
p(R, \theta)=-j k \rho_{0} c_{0} A \frac{1}{2 \pi R} D(\theta) e^{-j k R}
$$

where $\rho_{0}, c_{0}$ are density and sound speed of water, $A$ is the radiating piston area with radius a, $R$ is the distance from piston center to the far field point $\mathrm{Z}$ and $D(\theta)$ is the directivity function expressed by Eq. II.5 in Appendix II.

Our aim is to achieve an omnidirectional beam pattern on the $x-y$ plane in the frequency band of $45 \mathrm{kHz}-85 \mathrm{kHz}$. For that purpose, we place four radiating pistons spatially symmetric around origin as shown in Fig. 5. Each two piston, radiating opposite directions, corresponds to a back-to-back transducer whose detail is discussed in the next chapter. In the figure, $\mathrm{h}$ is the distance of transducer central axis to $y$-axis which is equal to baffle radius, $r$ is the distance of each piston center to $\mathrm{z}$ - axis, $\theta$ is the angle of far field point $\mathrm{Z}$ with respect to $+\mathrm{y}$-axis and $R$ is the distance of point $\mathrm{Z}$ to the origin. 


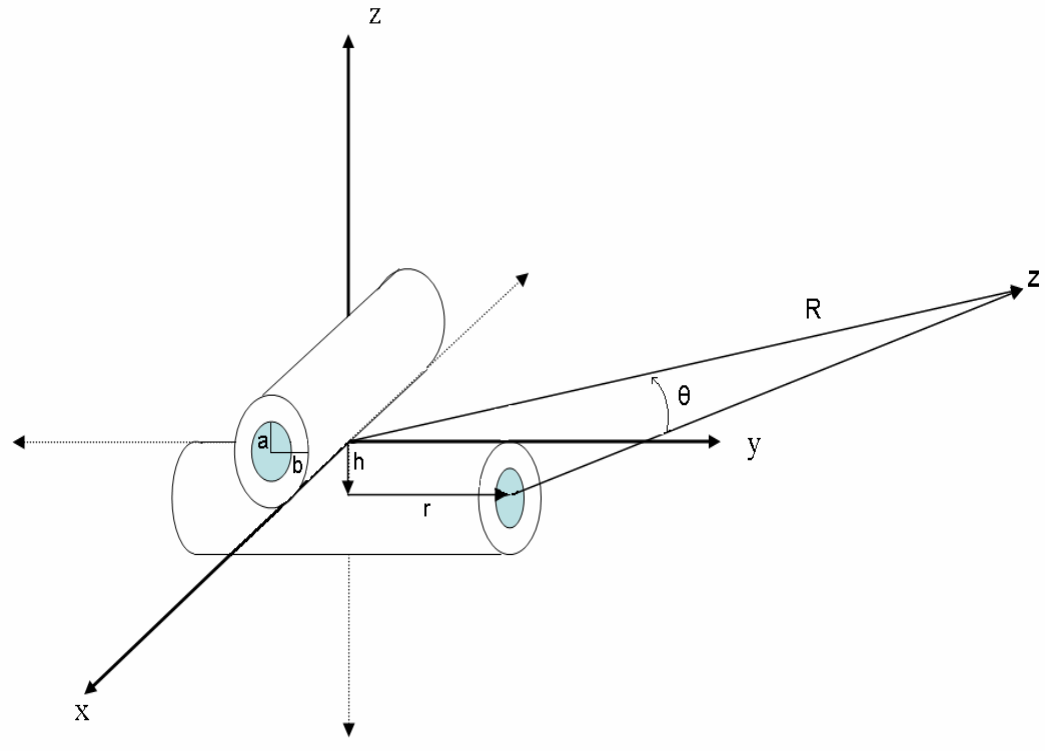

Figure 5. Four radiating pistons placed spatially symmetric around the origin.

Four radiating discs give a total pressure on point $\mathrm{Z}$ as;

$$
p_{t}(R, \theta)=-j k \rho_{0} A_{0} \frac{1}{2 \pi}\left(\frac{D_{1}(\theta) e^{-j k R_{1}}}{R_{1}} \frac{D_{2}(\theta) e^{-j k R_{2}}}{R_{2}} \frac{D_{3}(\theta) e^{-j k R_{3}}}{R_{3}} \frac{D_{4}(\theta) e^{-j k R_{4}}}{R_{4}}\right)
$$

Since $R>>$ h, $\mathrm{r}$ effective distances of point $\mathrm{Z}$ to the radiating pistons can be approximated as;

$$
\begin{gathered}
R_{1} \cong R-\sqrt{r^{2}+h^{2}} \cos \theta \\
R_{2} \cong R-\sqrt{r^{2}+h^{2}} \cos (\pi / 2-\theta) \\
R_{3} \cong R+\sqrt{r^{2}+h^{2}} \cos \theta \\
R_{4} \cong R+\sqrt{r^{2}+h^{2}} \cos (\pi / 2-\theta)
\end{gathered}
$$

In the above equations subscripts $1,2,3$ and 4 represents the radiating pistons directed towards $+\mathrm{y},-\mathrm{x},-\mathrm{y}$ and $+\mathrm{x}$ axes, respectively. 


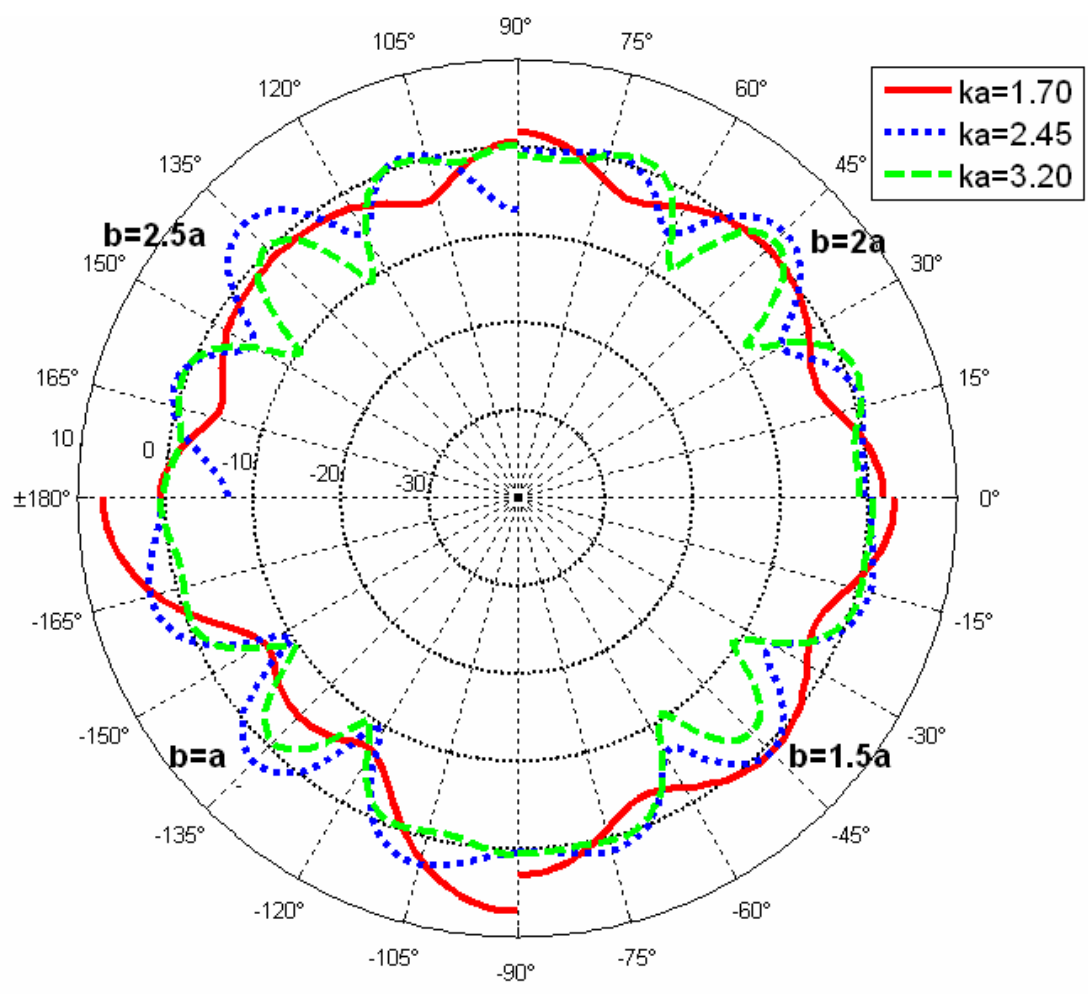

Figure 6. Normalized directivity function of a two back-to-back transducer in a finite baffle with $b=a, b=1.5 a, b=2 a, b=2.5 a$.

Normalized far field pressure response, $20 \log _{10}\left(\frac{\left|p_{t}\right|}{\left|\max \left(p_{1}\right)\right|}\right)$, of the geometry given in Fig. 5 is computed for various values of b, a and r. Fig. 6 shows the normalized pressure response for the baffle sizes $b=a, 1.5 \mathrm{a}, 2 \mathrm{a}$, and $2.5 \mathrm{a}, \mathrm{a}=9 \mathrm{~mm}$ and $r=25 \mathrm{~mm}$ and Fig. 7 those with $b=3 a$ and $b=8 a$.

Normalized far field pressure response with respect to disc radius a for $\mathrm{a}=5 \mathrm{~mm}, 9 \mathrm{~mm}, 15 \mathrm{~mm}$ and $20 \mathrm{~mm}$ while holding $\mathrm{b}=2 \mathrm{a}$ and $\mathrm{r}=25 \mathrm{~mm}$ is given in Fig. 8 and for the values of $r=15 \mathrm{~mm}, 25 \mathrm{~mm}, 35 \mathrm{~mm}$ and $45 \mathrm{~mm}$ with $\mathrm{a}=9 \mathrm{~mm}$ and $\mathrm{b}=2 \mathrm{a}$ is shown in Fig. 9 . 


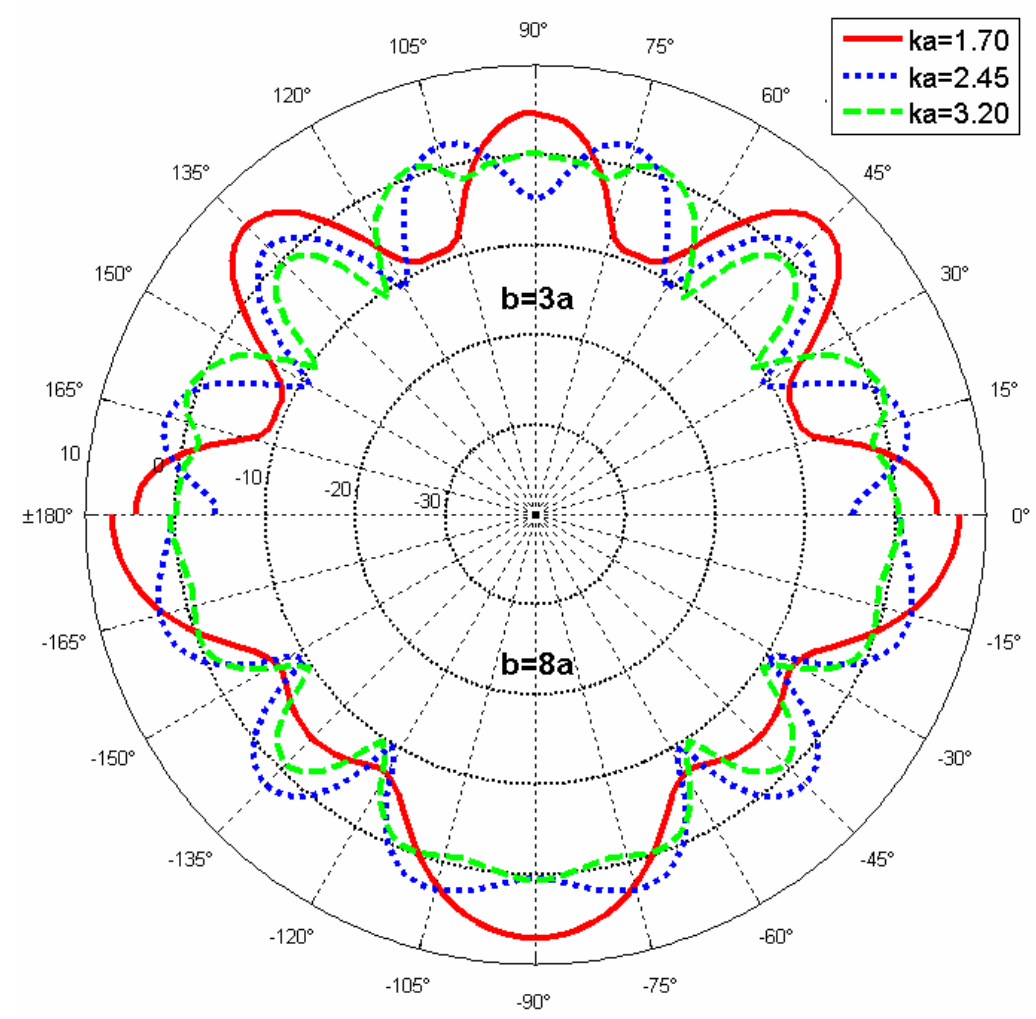

Figure 7. Normalized directivity function of a two back-to-back transducer in a finite baffle with $\mathrm{b}=3 \mathrm{a}$ and $\mathrm{b}=8 \mathrm{a}$

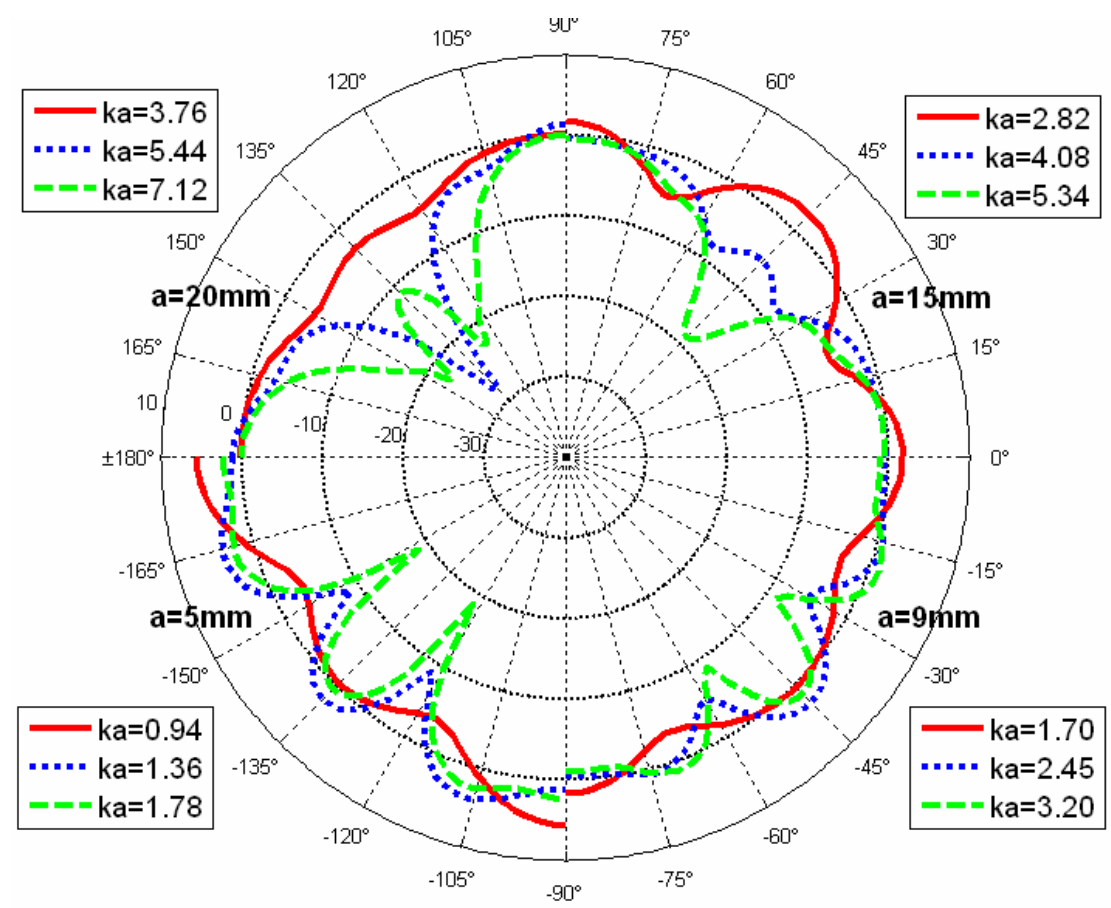

Figure 8. Normalized directivity function of a two back-to-back transducer in a finite baffle with $a=5 \mathrm{~mm}, a=9 \mathrm{~mm}, a=15 \mathrm{~mm}$ and $\mathrm{a}=20 \mathrm{~mm}$. 


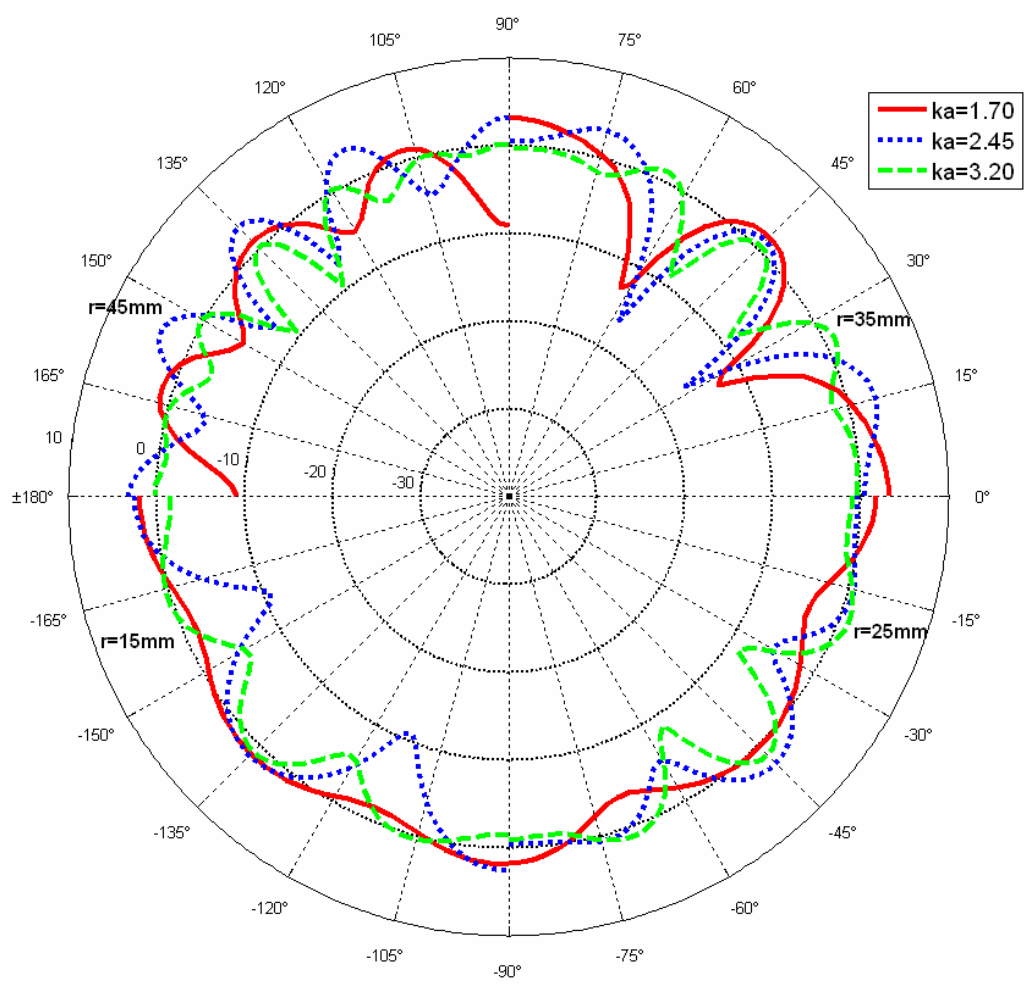

Figure 9. Normalized directivity function of a two back-to-back transducer in a finite baffle with $\mathrm{r}=15 \mathrm{~mm}, \mathrm{r}=25 \mathrm{~mm}, \mathrm{r}=35 \mathrm{~mm}$ and $\mathrm{r}=45 \mathrm{~mm}$.

Normalized pressure response results show that optimum transducer dimensions to achieve maximum omnidirectionality in the interested frequency band are $a=9 \mathrm{~mm}, b=2 a$ and $r=25 \mathrm{~mm}$. Far field vertical directivity pattern for these optimum dimensions is given in Fig. 10. 


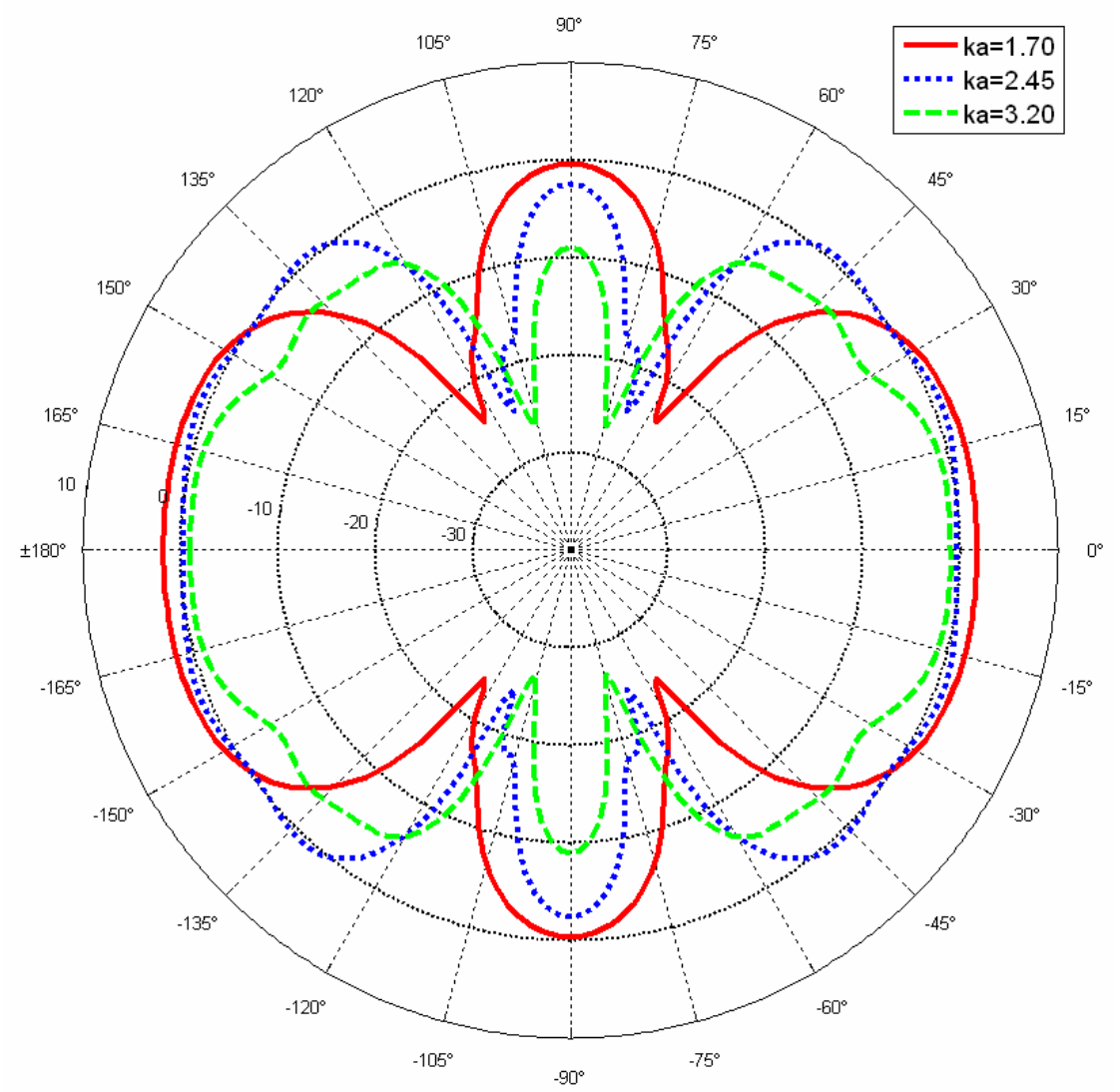

Figure 10. Normalized vertical directivity function of a two back-to-back transducer in a finite baffle with $\mathrm{r}=25 \mathrm{~mm}, \mathrm{~b}=2 \mathrm{a}$ and $\mathrm{a}=9 \mathrm{~mm}$.

In order to realize the effect of finite and infinite baffle on the radiation pattern, radiation pattern of a back-to-back transducer for both finite and infinite baffle is shown in Fig. 11. Radiation pattern, for a finite baffle, has a beamwidth more than $60^{\circ}$ in each half plane within the frequency band of 45 $\mathrm{kHz}-85 \mathrm{kHz}$ as shown in the lower half plane. Upper half plane corresponds to the common radiation pattern calculation with the assumption of infinite baffle. As it can be seen form the plot, infinite baffle would not be appropriate for practical purposes since it does not take reflections from the edges into account. Note that in the finite baffle case, there are some dips and peaks due to the interference of reflected waves from the edges of baffle. 


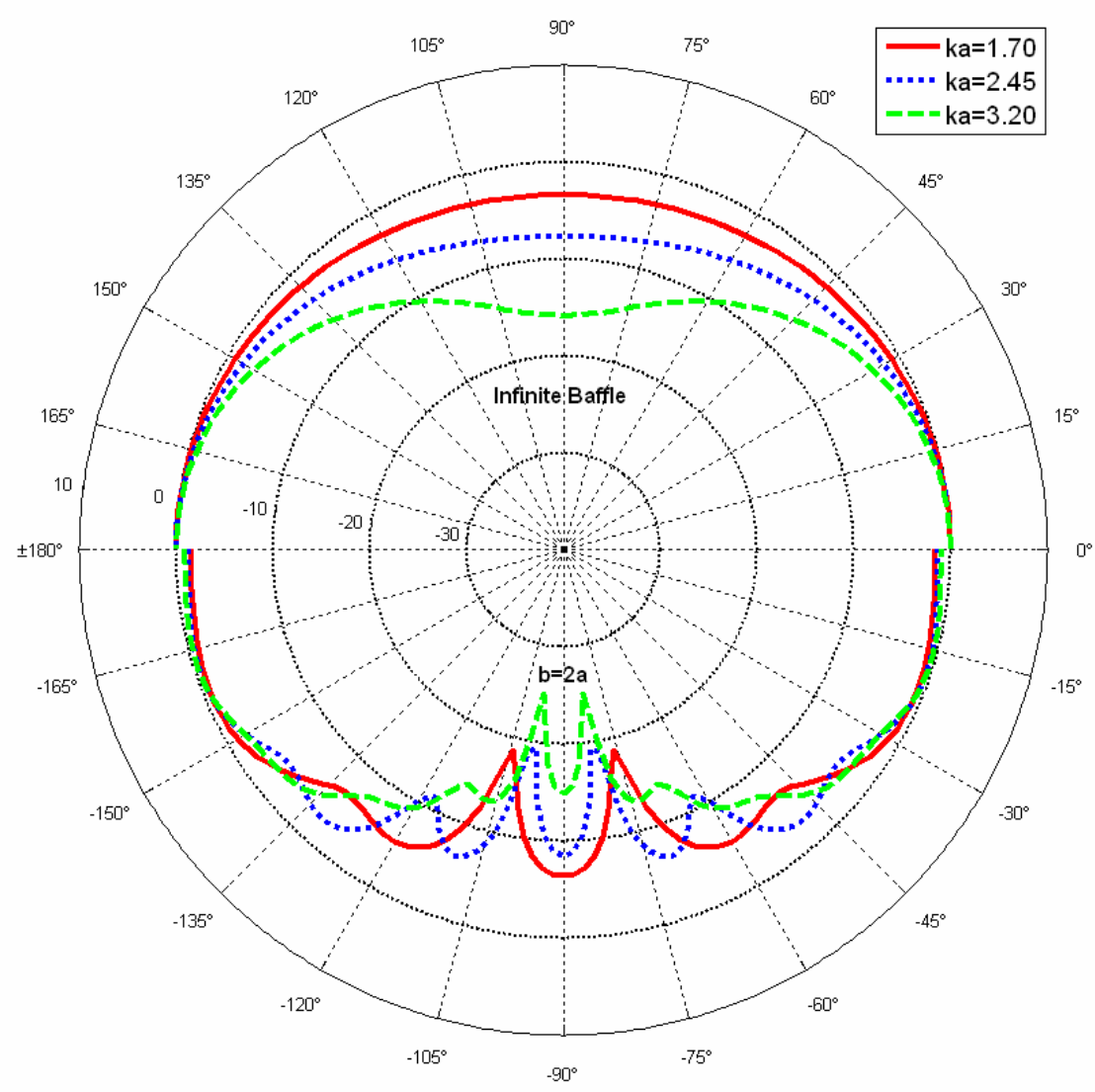

Figure 11. Normalized directivity function of a back-to-back transducer in an infinite baffle and a finite baffle with $b=2 a \mathrm{a}=9 \mathrm{~mm}$ and $\mathrm{r}=25 \mathrm{~mm}$.

Since the design of a back-to-back sandwich transducer depends also the dimensions of the elements, recursive optimization is made between radiation pattern analysis and a back-to-back transducer design that will be discussed in the next chapter. 


\section{Chapter 4}

\section{Design of a Back-to-Back Transducer}

Typical broadband sandwich transducers have three layers; active ceramic stack, a matching and a backing layers. Since piezoelectric ceramic elements are excited to vibrate in thickness mode, this type of transducers have high electromechanical coupling coefficient. Because of the large impedance mismatch between ceramic and water load, a quarter-wave matching layer is used to increase bandwidth. High impedance backing layer provide a nearly rigid boundary that allows ceramic rings to deliver large portion of the acoustical power to the load. While general design option is to obtain a halfwave resonator by making lengths of the backing and active section each one quarter-wavelength long, different length ratio of active and backing section can be used to adjust resonance frequency to the desired value. Sandwich transducers can endure high tensile strength by bolting ceramic elements with backing and matching layers under compressive stress. Furthermore, backing metal with high thermal conduction coefficient enables transducers to be driven safely at high power levels without critical temperature rise in ceramic rings.

In this chapter, we focus on the design of a back-to-back sandwich transducer. In the first section, design based on the electromechanical equivalent circuit analysis is described. We give details on the results obtained in the Finite Element Model (FEM) electromechanical analysis with ANSYS [14] in the second section. In the third section, we investigate the thermal behavior of the back-to-back transducer in a finite closed circular baffle under high electrical drive and give some important design criteria to prevent transducer from excessive heating. Thermal analysis of the transducer is carried out in Flux 2D finite element model. We discuss the cavitation problem and present cavitation 
limits of the designed transducer in section four. Finally, input impedance measurement result of a back-to-back transducer is shown in the last section.

\subsection{Design of a Back-to-back Transducer by Using Electromechanical Equivalent Circuit}

Two quarter wavelength elements each consists of two PZT-4 ceramic rings, a steel backing and a glass reinforced polymer (GRP) matching layers are placed in a back-to-back configuration to obtain half wavelength sandwich transducer as shown in Fig. 12.

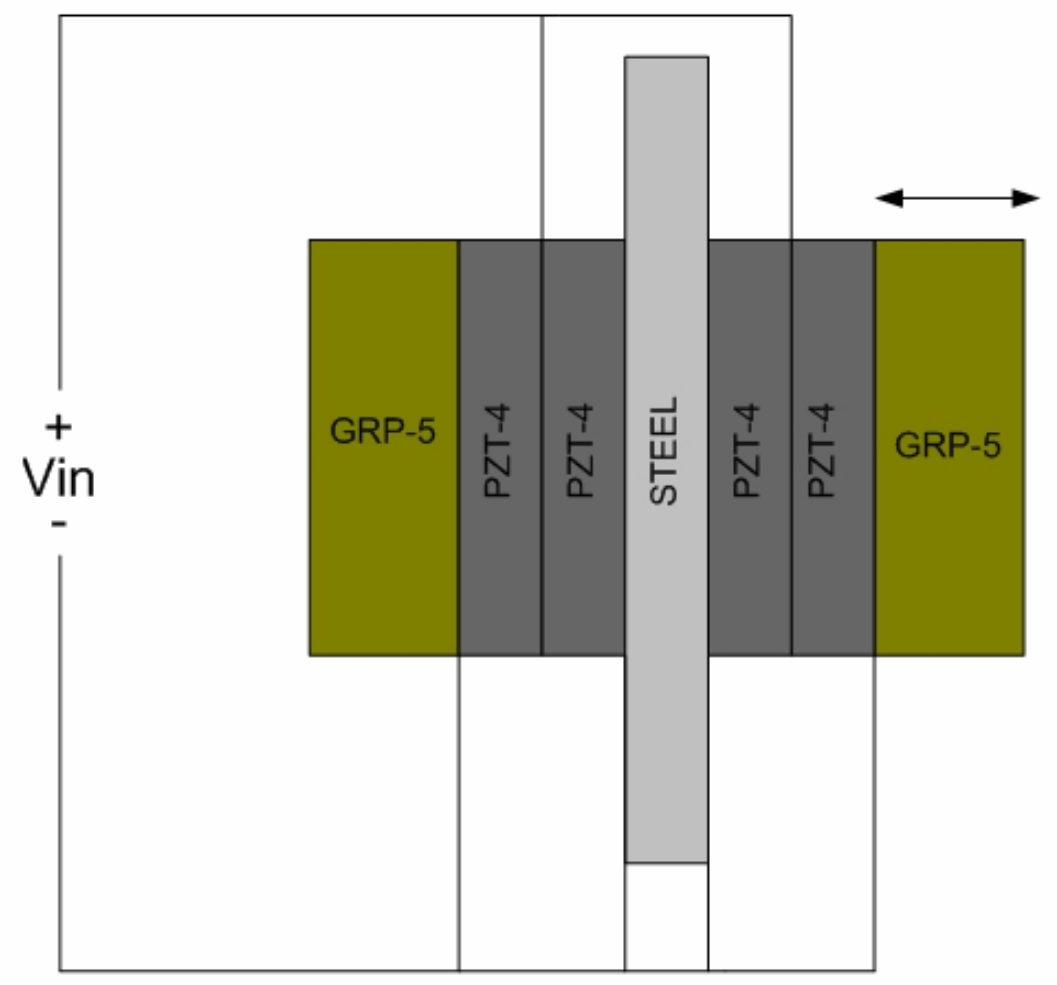

Figure 12. Side view of a back-to-back transducer 
Electromechanical equivalent circuit of the back-to-back transducer based on the transmission line theory, ignoring losses, can be represented by Fig. 13. Note that Mason equivalent model, given in Fig. 2, is used for the equivalent circuit of the PZT materials $[3,8,9,15]$.

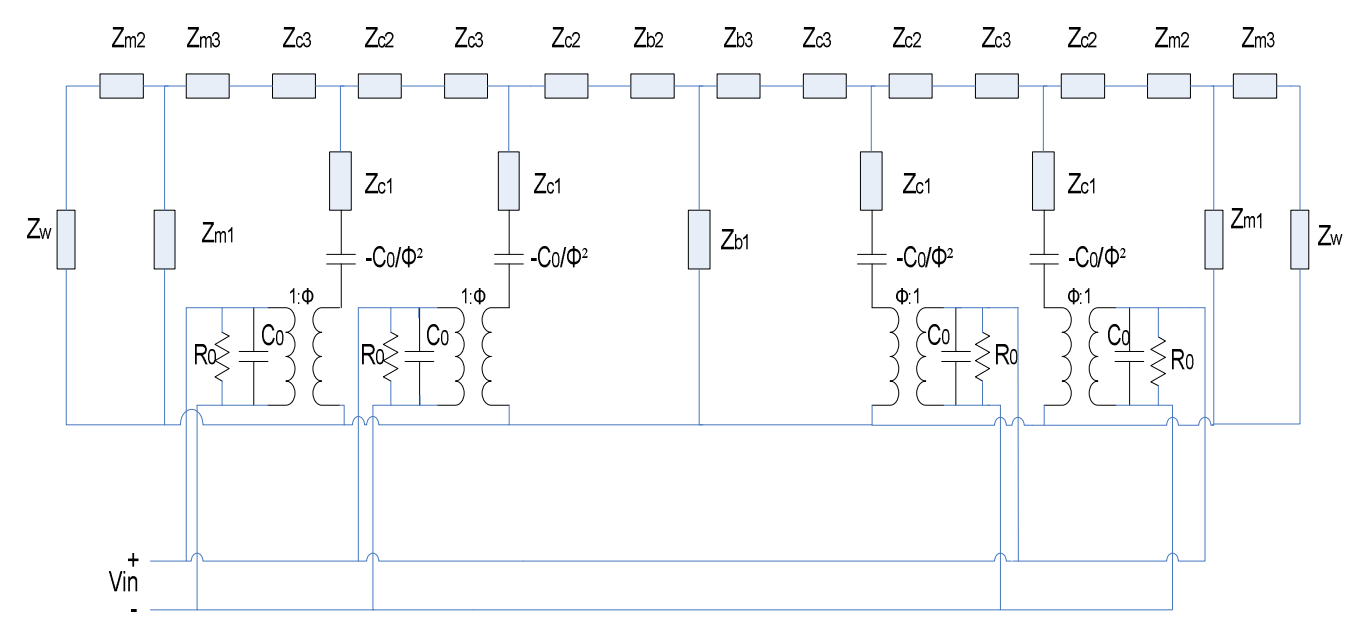

Figure 13. Electromechanical equivalent circuit of a back-to-back transducer

Using subscripts $\mathrm{b}$ for backing, $\mathrm{c}$ for ceramic rings and $\mathrm{m}$ for matching layer, $Z_{b 1}, Z_{b 2}$ and $Z_{b 3}$ are the impedances of backing metal, $Z_{m 1}, Z_{m 2}$ and $Z_{m 3}$ are the impedances of matching material, $Z_{c 1}, Z_{c 2}$ and $Z_{c 3}$ are those of piezoelectric ceramic rings. $Z_{w}$ is the radiation impedance of water which depends on the radii of disc and baffle, a and b. Their expressions are;

$$
\begin{aligned}
Z_{c 1} & =-\frac{j \rho_{c} c_{c} A_{0}}{\sin \left(k_{c} l_{c}\right)} \\
Z_{c 2}=Z_{c 3} & =j \rho_{c} c_{c} A_{0} \tan \left(\frac{k_{c} l_{c}}{2}\right) \\
Z_{b 1} & =-\frac{j \rho_{b} c_{b} A_{b}}{\sin \left(k_{b} l_{b}\right)}
\end{aligned}
$$




$$
\begin{gathered}
Z_{b 2}=Z_{b 3}=j \rho_{b} c_{b} A_{b} \tan \left(\frac{k_{b} l_{b}}{2}\right) \\
Z_{m 1}=-\frac{j \rho_{m} c_{m} A_{m}}{\sin \left(k_{m} l_{m}\right)} \\
Z_{m 2}=Z_{m 3}=j \rho_{m} c_{m} A_{m} \tan \left(\frac{k_{m} l_{m}}{2}\right) \\
R_{w}=\frac{1}{2}\left(1-\frac{J_{1}(2 k a)}{k a}-k b \frac{b^{2}}{a^{2}} \sum_{m=0}^{M} \mathfrak{R} c_{0} A\left[R_{w}+j X_{w}\right]\right. \\
X_{w}=\frac{1}{2}\left(1-\frac{H_{1}(2 k a)}{k a}-k b \frac{b^{2}}{a^{2}} \sum_{m=0}^{M} \mathfrak{I}\left(\tau_{m}\right)\left[1-\left[1-\left(\frac{a}{b}\right)^{2}\right]^{m+3 / 2}\right]\right)
\end{gathered}
$$

In the above equations $\rho, l$ and $A$ are density, thickness and area of the elements with their corresponding subscripts. Sound speeds in backing and matching layers can be found from the equation $c=\sqrt{\frac{E}{\rho}}$, and in those of the ceramic rings $c_{c}=\sqrt{\frac{C^{D} 33}{\rho_{c}}}$ where $E$ is the Young's modulus, $C_{33}^{D}$ is the elastic stiffness at constant charge density and $\rho_{c}$ is the density of piezoelectric ceramic rings. $k$ is the wave number and can be expressed as $k=\frac{\omega}{c}, H_{1}$ is the first order Struve function and $R_{w}$ and $X_{w}$ are the normalized radiation resistance and reactance of water. $c_{b}, \rho_{b}, c_{m}, \rho_{m}, c_{c}, \rho_{c}, \rho_{0}$ and $c_{0}$ are taken as $5130 \mathrm{~m} / \mathrm{s}, 7860 \mathrm{~kg} / \mathrm{m}^{3}, 2630 \mathrm{~m} / \mathrm{s}, 1890 \mathrm{~kg} / \mathrm{m}^{3}, 3800 \mathrm{~m} / \mathrm{s}, 7550 \mathrm{~kg} / \mathrm{m}^{3}, 1000$ $\mathrm{kg} / \mathrm{m}^{3}$, and $1500 \mathrm{~m} / \mathrm{s}$, respectively.

PZT4 with outer diameter $d_{2}=18 \mathrm{~mm}$, inner diameter $d_{1}=5.95 \mathrm{~mm}$ and thickness $l=5 \mathrm{~mm}$ is used as an active element. We adjust the length of the 
backing layer to $5.6 \mathrm{~mm}$ and piezoelectric ceramics with the backing layer resonates around $60 \mathrm{kHz}$. Then $10.6 \mathrm{~mm}$ GRP-5 matching layers are placed on both ends to increase the bandwidth. Since the exact properties of GRP-5 are not known, sound speed and poisson ratio values are approximated from other GRP materials.

Fig. 14 shows conductance-susceptance plot obtained from equivalent circuit analysis and power gain from one piston to the electrical terminals is given in Fig. 15 [16].

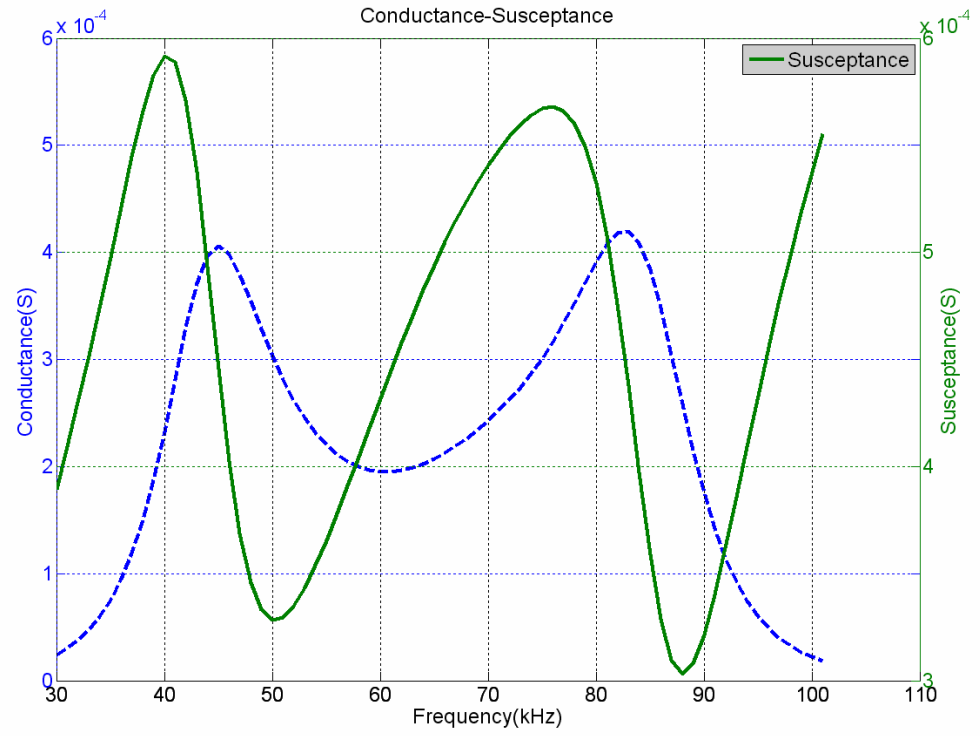

Figure 14. Conductance-Susceptance seen from the electrical terminals obtained from equivalent circuit analysis 


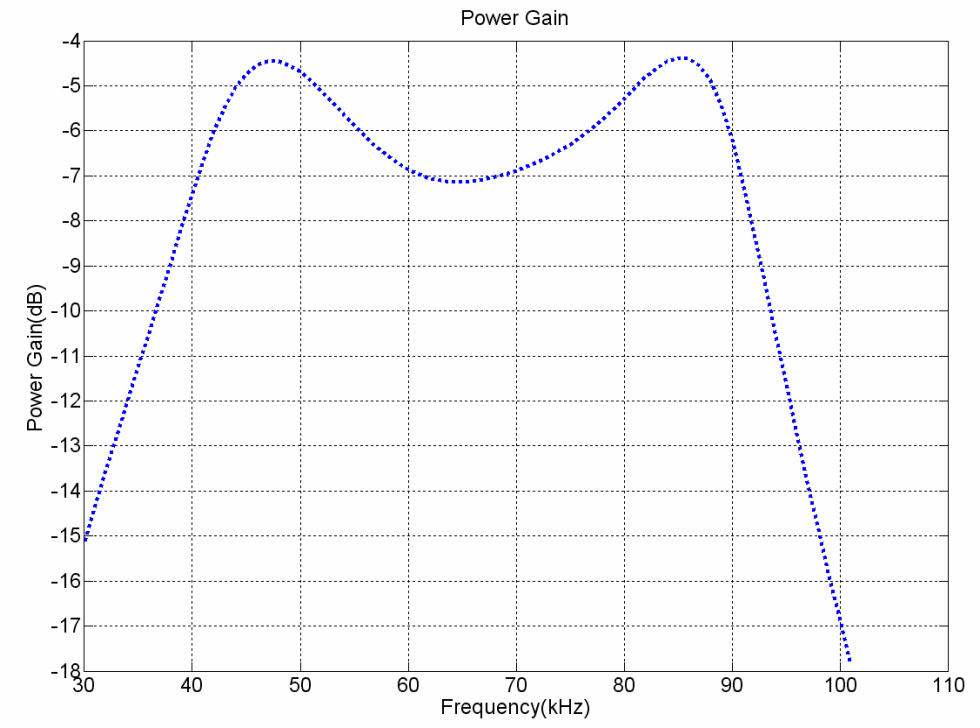

Figure 15. Power gain from one piston of a back-to-back transducer to the electrical terminals

In underwater acoustic systems it is customary to characterize the strength of a projector in terms of TVR and SPL defined in the section "Basic Definitions and Units". TVR and SPL of each piston of the back-to-back transducer are shown in Fig. 16 and Fig. 17, respectively.

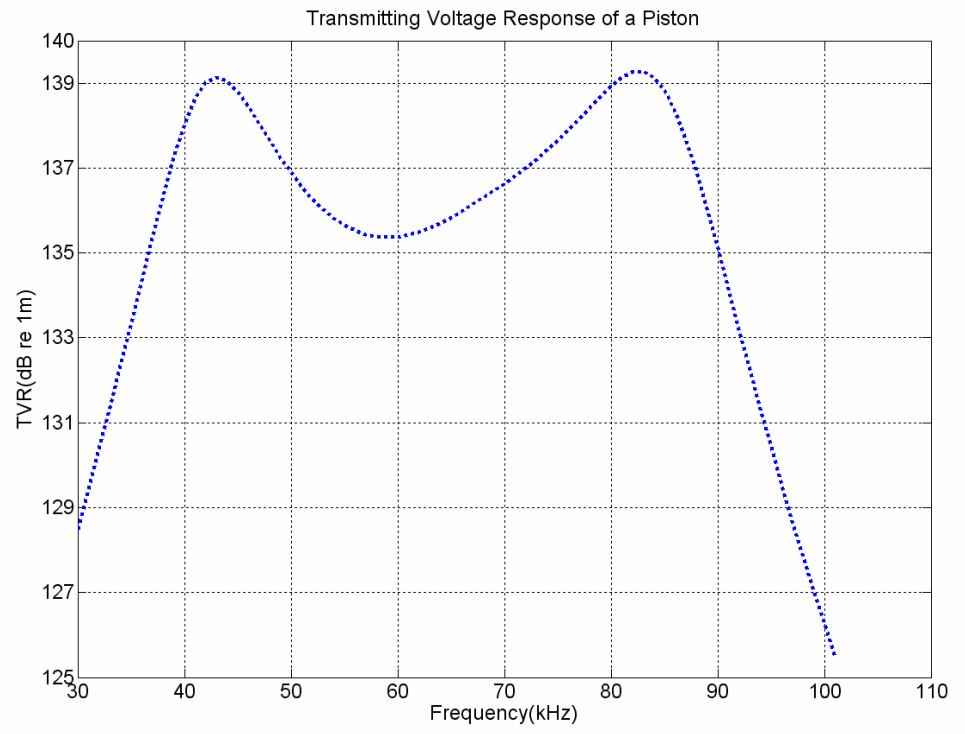

Figure 16. Transmitting voltage response of each piston of a back-to-back transducer 


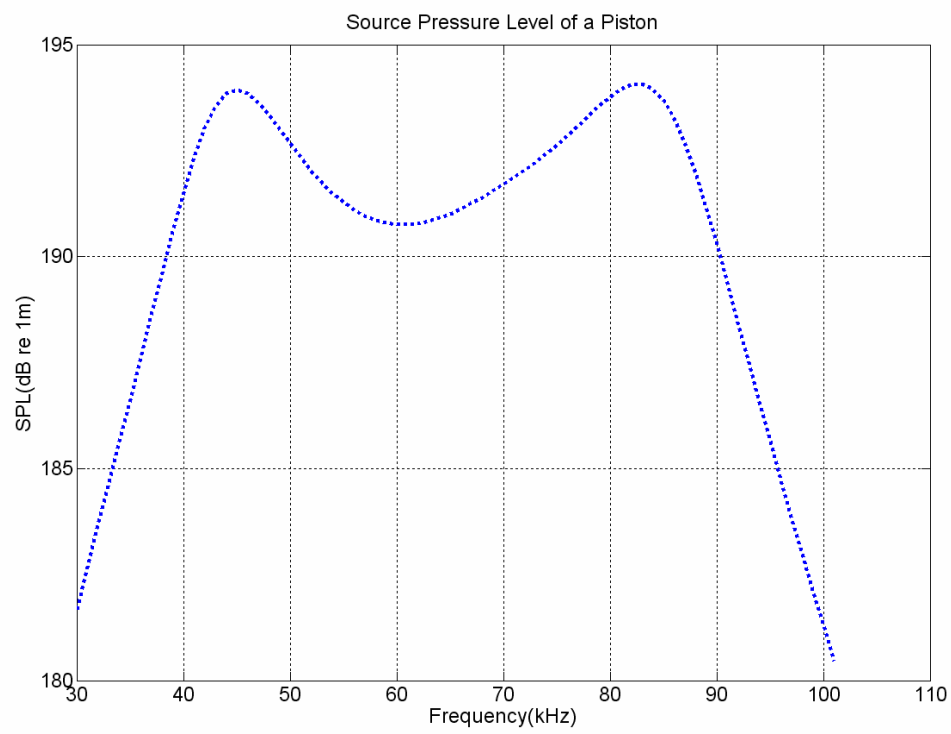

Figure 17. Source pressure level of each piston of a back-to-back transducer

Above results show that operating frequency band of the back-to-back transducer is approximately $40 \mathrm{kHz}-90 \mathrm{kHz}$ and $\% 75$ bandwidth is achieved. Note that, conductance-susceptance plot does not reveal any radial modes since only 33 mode vibrations are taken into account. In the next section, lengths of the backing and matching layers are tuned using finite element model and exact operating band is determined.

\subsection{Finite Element Model (FEM) of the Back-to-Back Transducer}

Equivalent circuit model simulates one dimensional electro-mechanical systems. It assumes ideal conditions for the transducers and none of the effects such as reflections, radial and shear mode vibrations is included. Furthermore, sound speed is assumed to be constant within the medium which is impractical. In fact, as the thickness become comparable to the lateral dimensions of the medium, sound speed decreases. On the other hand, finite element method divide the transducer to a large number of lumped or distributed elements spatially placed throughout the transducer and computes the three dimensional 
behavior of the transducer. Electromechanical analysis of the transducer can be performed in both 2D and 3D in FEM. Depending on the shape of the transducer, if there is symmetry, 2D axi-symmetric model provide the fastest solution.

FEM uses fluid elements, where pressure field is described at the nodes and mechanical elements are described with displacement values at the nodes. Thus, a fluid surface interface, FSI, is used to couple mechanical and fluid elements at the interface. As a boundary condition, outer radius of the fluid is defined as an infinite acoustic plane such that there is no reflecting waves back to the transducer.

Using the symmetry of the back-to-back transducer, 2D FEM model of the back-to-back transducer is constructed with ANSYS as shown in Fig. 18 and Fig. 19 where only quarter of the transducer is modeled due to symmetry [17]. Piezoelectric coefficients used for the finite element analysis are given in Appendix I. Note that back-to-back transducer, given in Figure 12, is placed along y-axis such that two of the ceramic rings polarized along $+y$ axis and the other two along the $-\mathrm{y}$ axis. PLANE13 is used for the steel, PZT-4 and GRP-5 where UX, UY and VOLT degrees of freedoms (DOFs) for PZT-4 elements and UX and UY DOF's for those of steel and GRP elements are chosen. PLANE13 element has a 2-D piezoelectric and structural field capability that appropriate for our analysis. FLUID29 is used for modeling the fluid medium and for the interface in fluid/structure. As an infinite acoustic absorbing boundary, outer circle in Fig. 18, FLUID129 is the only option for 2D analysis which simulates the absorbing effects of a fluid domain that extends to infinity. Finally, CIRCU94 is selected for those of circuit elements which are used for admittance analysis. 


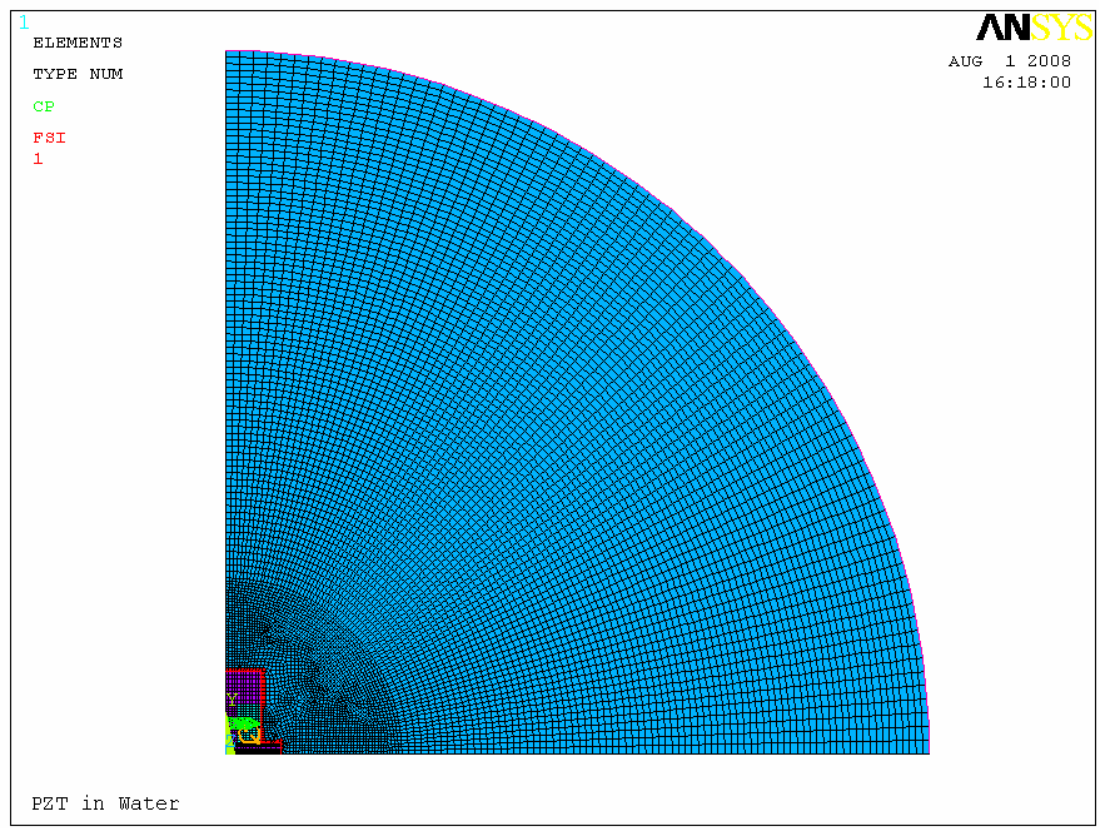

Figure 18. Overall FEM model

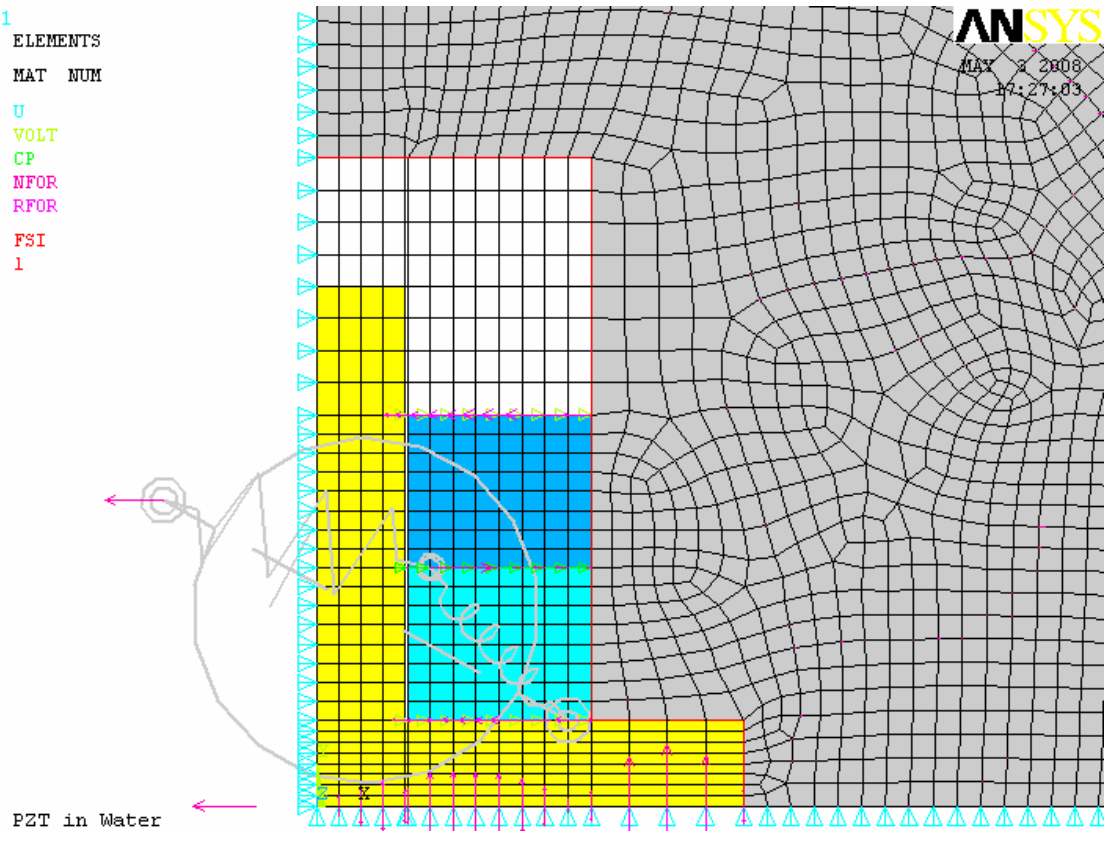

Figure 19. FEM of the back-to-back transducer 
Other boundary conditions for axi-symmetric model are; all the nodes in $\mathrm{x}=0$ line cannot move along the $\mathrm{x}$-axis, all the nodes in $\mathrm{y}=0$ line cannot move along the y-axis.

We perform harmonic analysis and plot conductance and susceptance seen at the electrical terminals given in Fig. 20 and Fig. 21, respectively. The admittance predicted by FEM analysis slightly differs from admittance obtained by equivalent circuit, particularly at the higher end of the frequency range. In fact, this is an expected result since equivalent circuit model is a onedimensional solution and does not take into account other effects such as radial and shear mode vibrations. Furthermore, in the equivalent circuit model, sound speed of the materials are assumed to be ones given as bulk velocity in the literature [3], but as the ratio of lateral dimension to longitudinal dimension changes, sound speed changes as well. The lowest radial resonance frequency of the transducer takes place near $100 \mathrm{kHz}$. This resonance is not accounted for in the equivalent circuit model, whereas it is considered in FEM analysis. The rise in the conductance values above $85 \mathrm{kHz}$ is due to this effect.

TVR and SPL of the back-to-back transducer are given in Fig. 22 and Fig. 23. Note that the results are quite close to the ones obtained from the equivalent circuit analysis except that operating frequency band is larger in the equivalent circuit model due to reasons discussed above. Since ANSYS does not calculate acoustic power, we calculate the acoustic power as;

$$
P_{a}=\Re\left(\frac{1}{2} F u^{*}\right)
$$

where $F$ is the force $u$ is the average velocity on the surface of piston . $F$ is found by multiplying average pressure on the surface nodes with the area. 


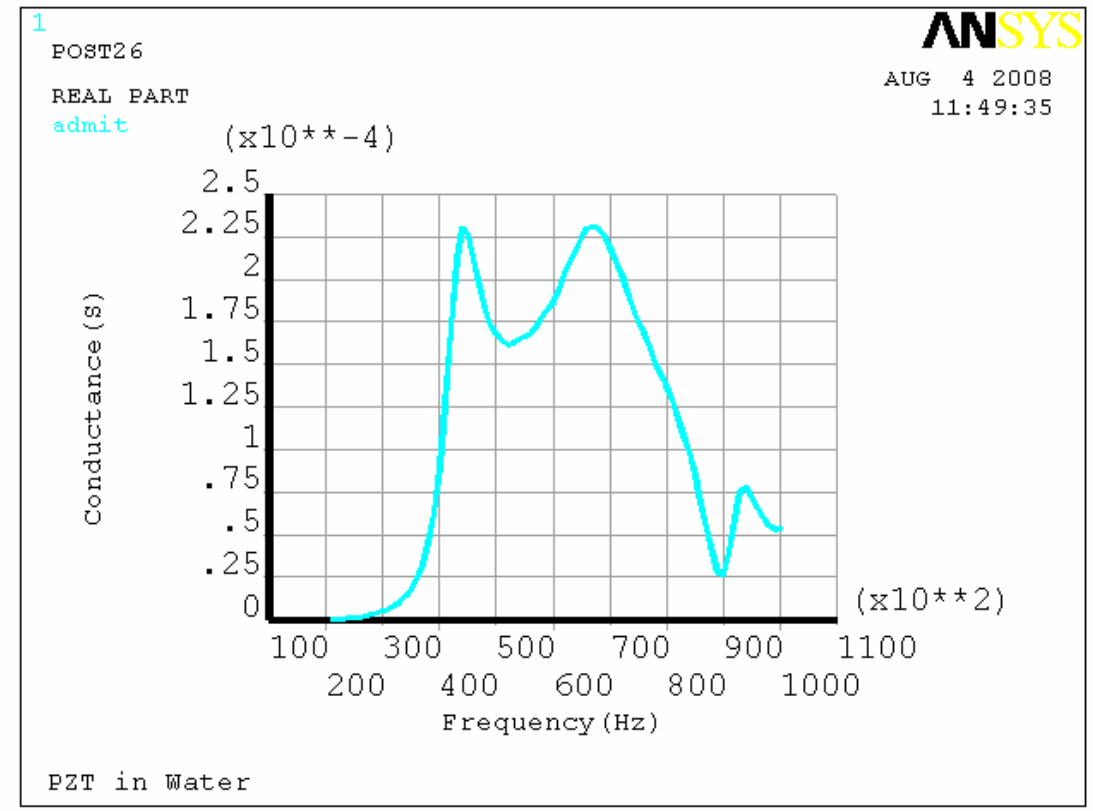

Figure 20. Conductance seen from the electrical terminals obtained from FEM analysis.

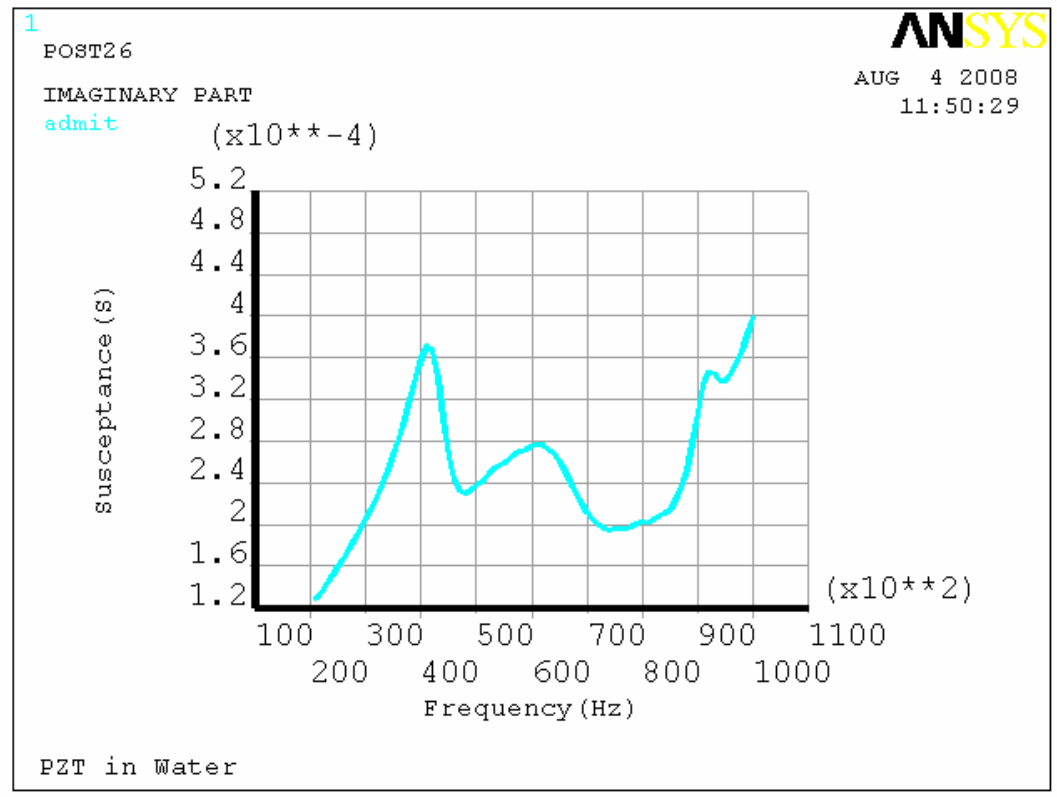

Figure 21. Susceptance seen from the electrical terminals obtained from FEM analysis 


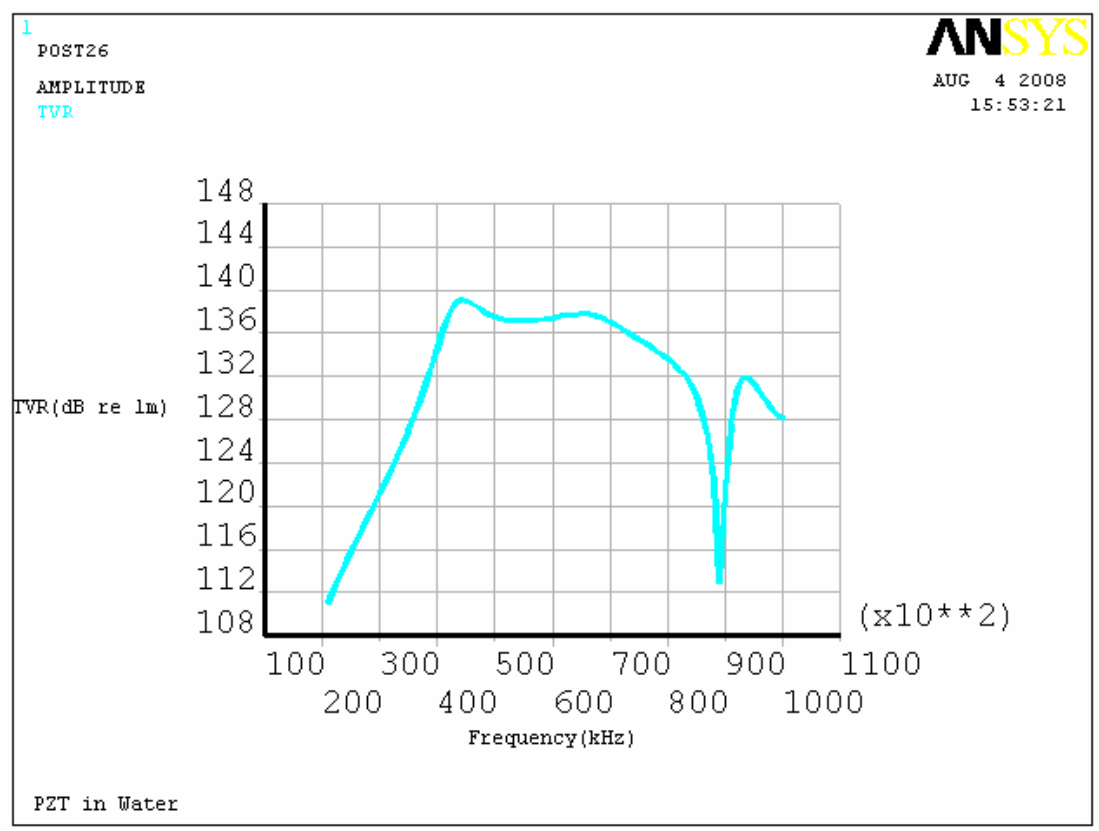

Figure 22. Transmitting voltage response of one piston of a back-to-back transducer obtained from FEM analysis

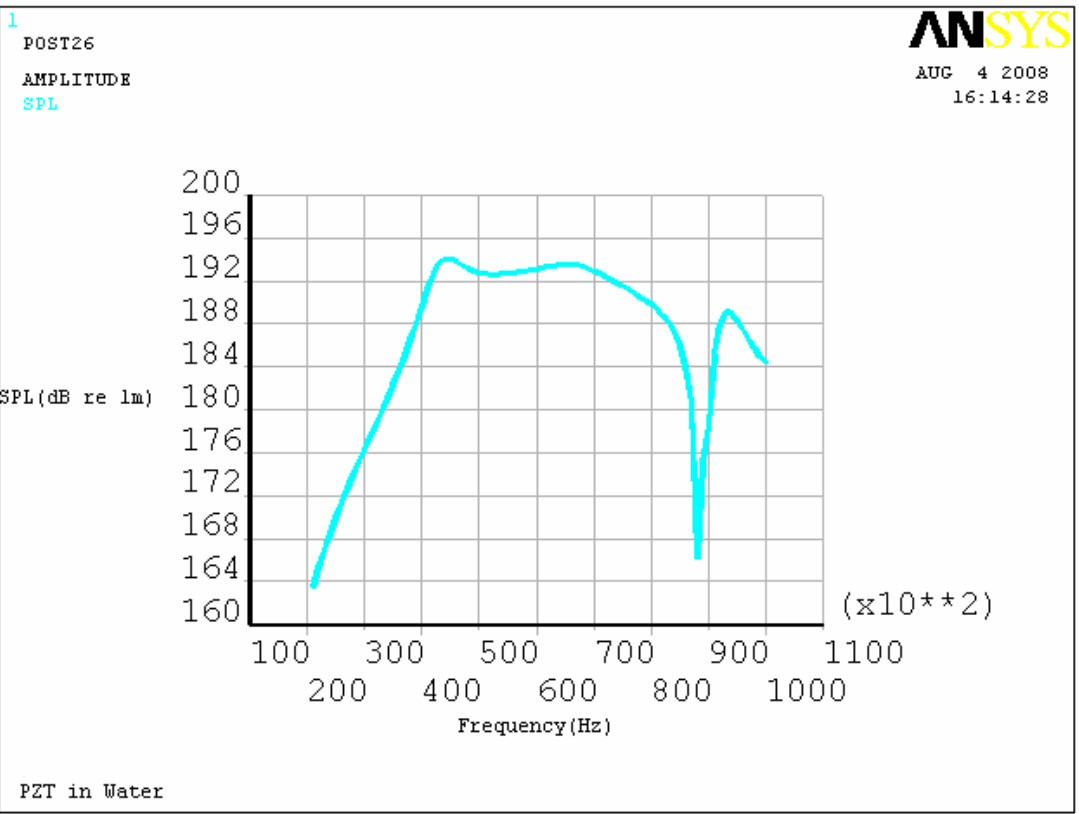

Figure 23. Source pressure level of one piston of a back-to-back transducer 


\subsection{Thermal Analysis of the back-to-back Transducer with Finite Element Model (FEM)}

Heat characteristic of high power sandwich transducers is an important consideration. PZT ceramics have very small thermal conduction coefficients, around $1-2 \mathrm{~W} /\left(\mathrm{m}^{\circ} \mathrm{K}\right)$, they may generate considerable heat when they are driven at high power levels. Backing metal with high thermal conduction coefficient enables sandwich transducers to be driven safely at high power levels without critical temperature rise in ceramic rings. Depending on the power level, however, backing material may be insufficient such that one may need to look for other cooling routes to get rid of excessive heat.

In this section, we analyze the thermal characteristics of the back-to-back transducer at continuous electrical drive of $1000 \mathrm{~V}$ both in air and water. We also examine the effect of coating and adhesive materials and demonstrate that proper choice of adhesive, used to glue steel, ceramic rings and GRP and to fill the gap between transducer and steel baffle, and coating materials can reduce temperature rise in the ceramics significantly.

Electrical power loss in the piezoelectric ceramic ring is given by;

$$
P_{d}=\omega E^{2} V \varepsilon \tan \delta
$$

where $\omega$ is angular frequency, $E$ is the electric field, $V$ is the volume, $\varepsilon$ is the free dielectric constant and $\tan \delta$ is the dissipation factor [18].

Thermal properties of back-to-back transducer with $b=2 \mathrm{a}$ are analyzed using Flux2D finite element program [19]. We place back-to-back transducer inside an steel cylinder whose length is equal to the length of the back-to-back transducer, outer radius is twice of the back-to-back transducer and thickness of the steel cylinder is $4 \mathrm{~mm}$. Between the steel cylinder baffle and transducer, Loctite 3873 
acrylic epoxy with thermal conductivity $1.25 \mathrm{~W} / \mathrm{m}^{\circ} \mathrm{K}$ is assumed to be placed [20]. FEM model for thermal analysis is shown in Fig. 24.

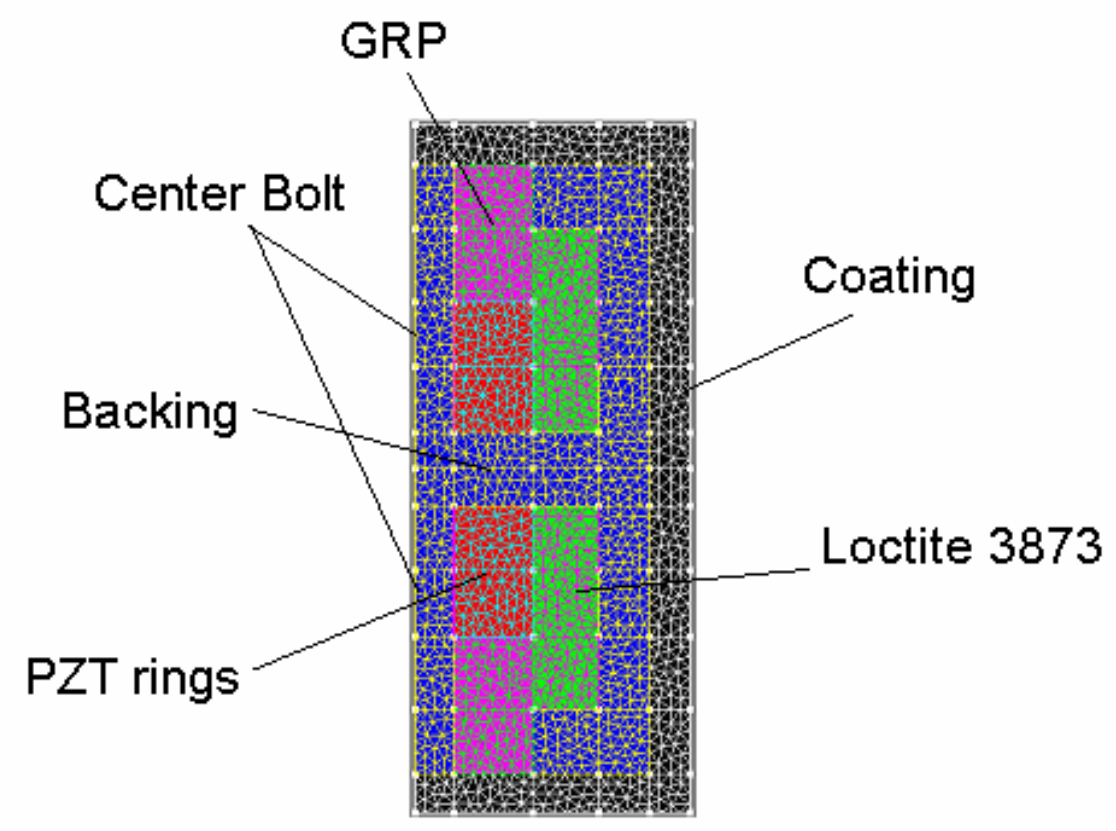

Figure 24 FEM model of back-to-back transducer with baffle

Thermal conductivity of PZT rings and GRP matching layer are $0.2 \mathrm{~W} / \mathrm{m}^{\circ} \mathrm{K}$ and $1.8 \mathrm{~W} / \mathrm{m}^{\circ} \mathrm{K}$, respectively. Convection coefficient of water and air are taken as $1350 \mathrm{~W} / \mathrm{m}^{2 \circ} \mathrm{K}$ and $22 \mathrm{~W} / / \mathrm{m}^{2 \circ} \mathrm{K}$ respectively and outside temperature is assumed to be $16^{\circ} \mathrm{C}$. Transducer is driven with $1000 \mathrm{Vrms}$ at $80 \mathrm{kHz}$ where $\tan \delta$ is 0.01 .

Fig. 25 and Fig. 26 shows in-air steady state temperature distribution of back-to-back transducer and transient temperature response of the node at the inner surface of PZT rings. Maximum heating occurs at the inner surface of the rings and the center bolt, as expected, since the longest path to the water for the heat transfer is from inner part of PZT rings. Note that temperature rises to 123 ${ }^{\circ} \mathrm{C}$ inside the ceramics which is critical since the properties of PZT ceramics 
change dramatically with the temperature as given in the datasheets [7]. It takes approximately 4000 s for transducer to reach steady state.
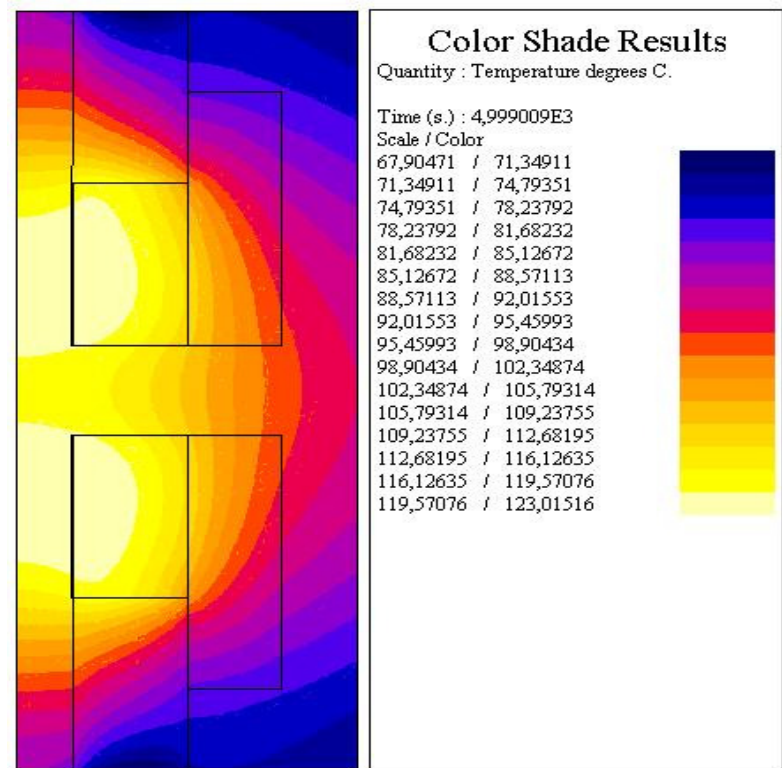

Figure 25. In-air steady state temperature distribution of back-to-back transducer

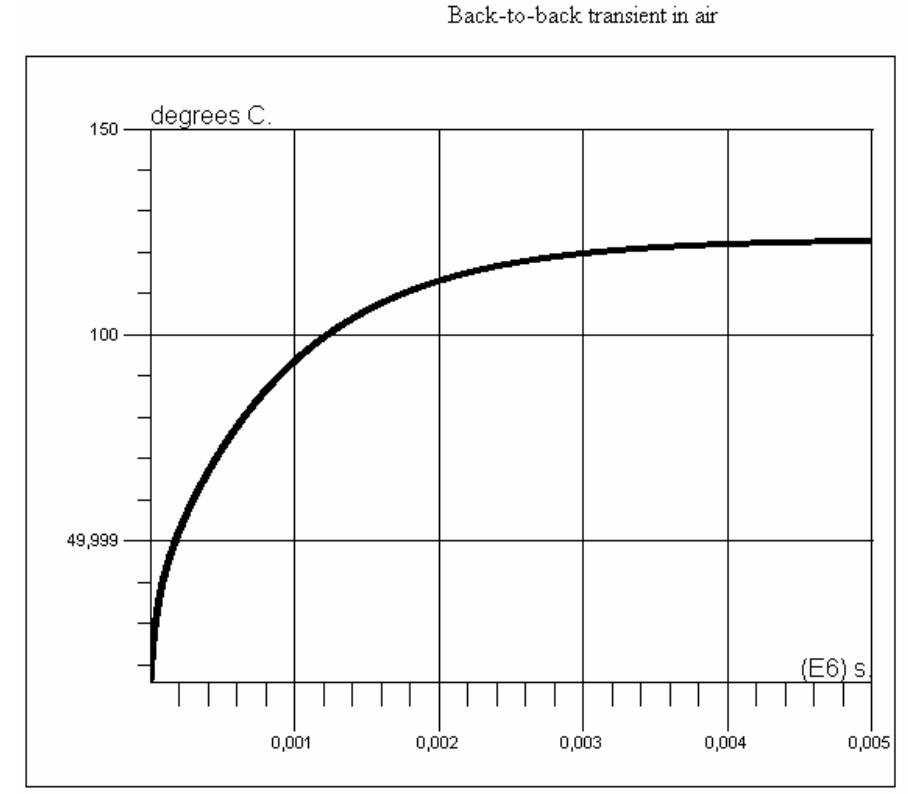

Figure 26. In-air transient temperature response of the node at the inner surface of PZT 
In-water steady state temperature distribution of back-to-back transducer and transient temperature response of the element at the inner surface of PZT rings are given in Fig. 27 and Fig. 28, respectively. Since the convection coefficient of the water is much higher than the air, steady state temperature inside $\mathrm{PZT}$ rings decreases to $54^{\circ} \mathrm{C}$ and required time for transducer to reach steady state decreased to $500 \mathrm{~s}$.

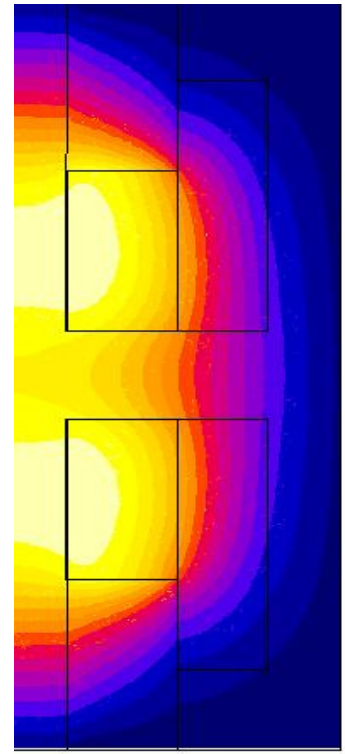

Color Shade Results Quantity : Temperature degrees C.

Time (s.) : 999,009999

Scale / Color

$16,10918 / 18,51692$

$18,51692 / 20,92467$

20,92467 / 23,33241

23,33241 / 25,74016

$25,74016 / 28,1479$

$28,1479 / 30,55565$

30,55565 / 32,96339

$32,96339 / 35,37114$
35,$37114 ; 3777888$
37,77888

$37,77888,40,18663$

40,18663 / 42,59437

42,59437 / 45,00212

45,00212 / 47,40986

47,40986 / 49,81761

49,81761 / 52,22535

52,22535 / 54,6331

Figure 27. In-water steady state temperature distribution of back-to-back transducer 
Back-to-back Transient In Water

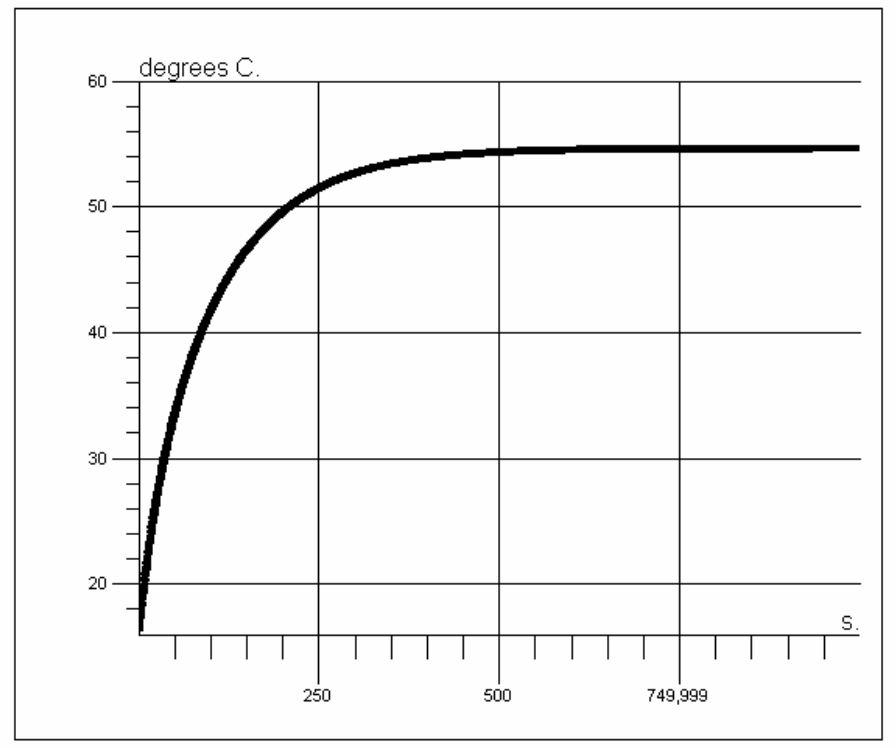

Figure 28. In-water Transient temperature response of the node at the inner surface of PZT

Transducers are generally coated with a material, as shown in Fig. 24, whose specific acoustic impedance is close to that of water and has a low transmission loss. Depending on the thickness and thermal conductivity of the coating material, thermal properties of the transducer may vary significantly. In order to observe the effect of coating material on the thermal characteristics of the transducer, transducer is assumed to be coated with two different materials. Fig. 29 shows in-water steady state temperature distribution of the back-to-back transducer with a $3 \mathrm{~mm}$ Loctite 3873 acrylic epoxy coating whose thermal conductivity is $1.25 \mathrm{~W} / \mathrm{m}^{\circ} \mathrm{K}$ and Fig. 30 with that of polyurethane coating whose thermal conductivity is $0.2 \mathrm{~W} / \mathrm{m}^{\circ} \mathrm{K}$, respectively. Results show that if heat transfer from transducer to the water is sufficient, temperature rise in the ceramics is not critical. Temperature decreases from $75^{\circ} \mathrm{C}$ to $58^{\circ} \mathrm{C}$ in the PZT ceramics with the use of high thermal conductivity epoxy compare to polyurethane. Therefore, coating material has to be considered not only for acoustic properties but also thermal properties, especially for high power applications. With the choice of Loctite 3873 epoxy, the transducer is capable of delivering acoustic power in excess of $125 \mathrm{~W}$ from each piston where maximum 
temperature in ceramic rings is $58.6^{\circ} \mathrm{C}$. At this drive level, average electrical power dissipation in four PZT rings is $7.9 \mathrm{~W}$.
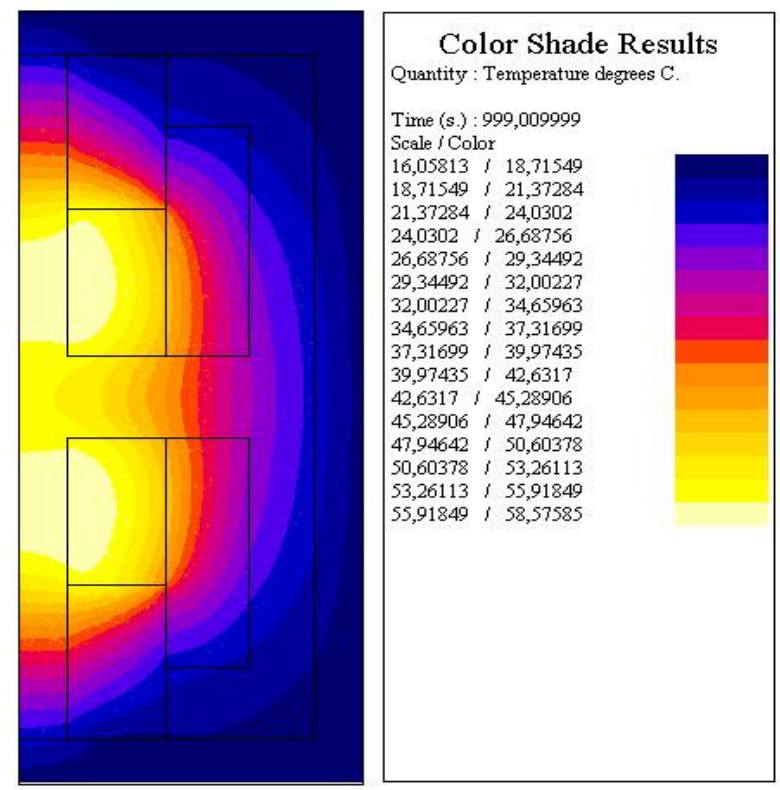

Figure 29. In-water steady state temperature distribution of back-to-back transducer with epoxy coating
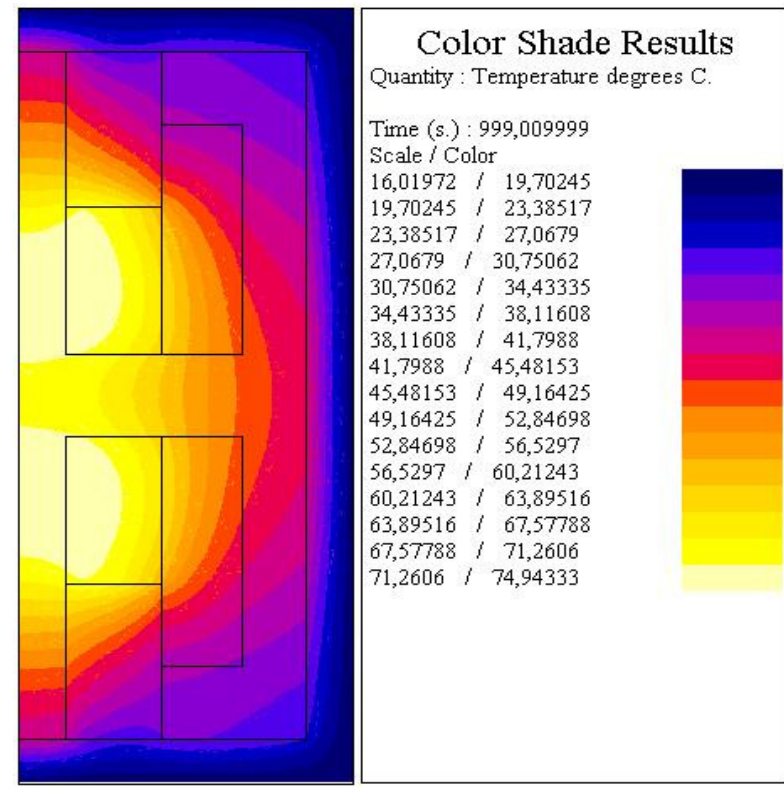

Figure 30. In-water steady state temperature distribution of back-to-back transducer with polyurethane coating 
Finally, we analyze the impact of the filling material between the steel cylinder baffle and the back-to-back transducer on the thermal characteristics of the transducer. Fig. 31 shows the in water steady state temperature distribution of the back-to-back transducer where polyurethane is used for both coating and filling material. This configuration is the same of that in Figure 30 where filling material is Loctite 3873 acrylic epoxy and polyurethane is the coating material. Temperature inside the PZT rings rises from $75^{\circ} \mathrm{C}$ to $120^{\circ} \mathrm{C}$ which is quite dangerous for PZT ceramics. Therefore, we may conclude that, high power applications require a careful design consideration from thermal point of view so that proper operation of the transducer could be achieved. Both filling and coating material should have as high thermal conductivity as possible for safe operation of the transducer.
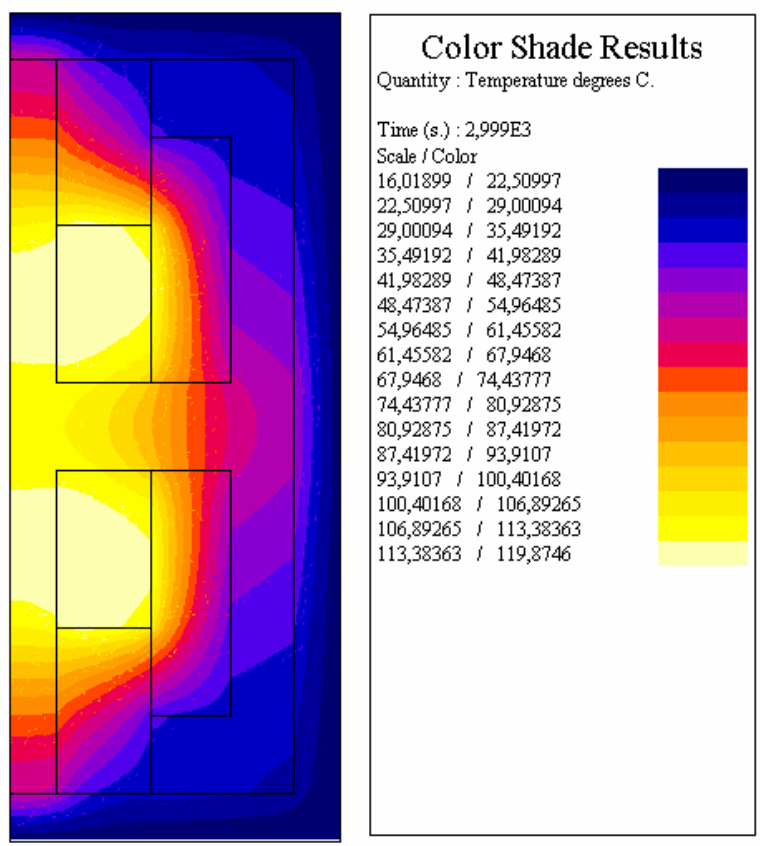

Figure 31. In-water steady state temperature distribution of back-to-back transducer with polyurethane filling and coating 


\subsection{Cavitation Limit Analysis of the Back-to-back Transducer}

In this section we investigate the cavitation problem of the back-to-back transducer which, in fact, limits the acoustic power capability of the transducer in shallow waters. Cavitation occurs when amplitude of the acoustic pressure exceeds the hydrostatic pressure. Air bubbles take place on the surface of the transducer act as cavitation nuclei during the negative cycles and these air bubbles cause scattering of the sound [21]. Therefore, acoustic power of the transducer may be limited by cavitation.

Cavitation limit of transducers depends on some variables such as near-field structure of the transducer, operating depth and percentage of dissolved air in the water. Akulichev and Il'ichev give acoustic cavitation thresholds of sea water in different regions of the world, in which experimental measurements were made between 1963 and 1987 [22]. Sherman defined the cavitation limited intensity at the piston surface of the back-to-back transducer as;

$$
I_{c}=\frac{\gamma}{3}\left(1+\frac{h}{34}+T\right)^{2} \quad W / \mathrm{cm}^{2}
$$

where $h$ is the depth in feet, $T$ is the effective tensile strength of water in atm.. And $\gamma$ is the dimensionless defined as;

$$
\gamma=\frac{\left(\frac{R_{r}}{\rho c A}\right)}{\left(\frac{p_{m} \mid}{\rho c u_{0}}\right)^{2}}
$$

$R_{r}$ is the radiation resistance, $u_{0}$ is the velocity, $A$ is the radiating area and $p_{m}$ is the maximum pressure amplitude in the near field for the velocity of $u_{0}$ [3]. If $k a \geq \pi$, at least one maxima of pressure occurs along the axis which is given by; 


$$
p=2 \rho c u_{0}
$$

and when $k a<\pi$ maximum pressure is on the surface of the piston and it is equal to;

$$
p=2 \rho c u_{0} \sin \left(\frac{k a}{2}\right)
$$

Using the Eq. 4.5 and $4.6 \gamma$ values for $30 \mathrm{kHz}-100 \mathrm{kHz}$ range are calculated as in Fig. 32. Fig. 33 shows the cavitation limited intensities for various frequencies. Since the radiating area of one piston of the back-to-back transducer is $2.544 \mathrm{~cm}^{2}$, cavitation limited acoustic power from one piston with respect to frequency and depth is demonstrated in Figure 42.

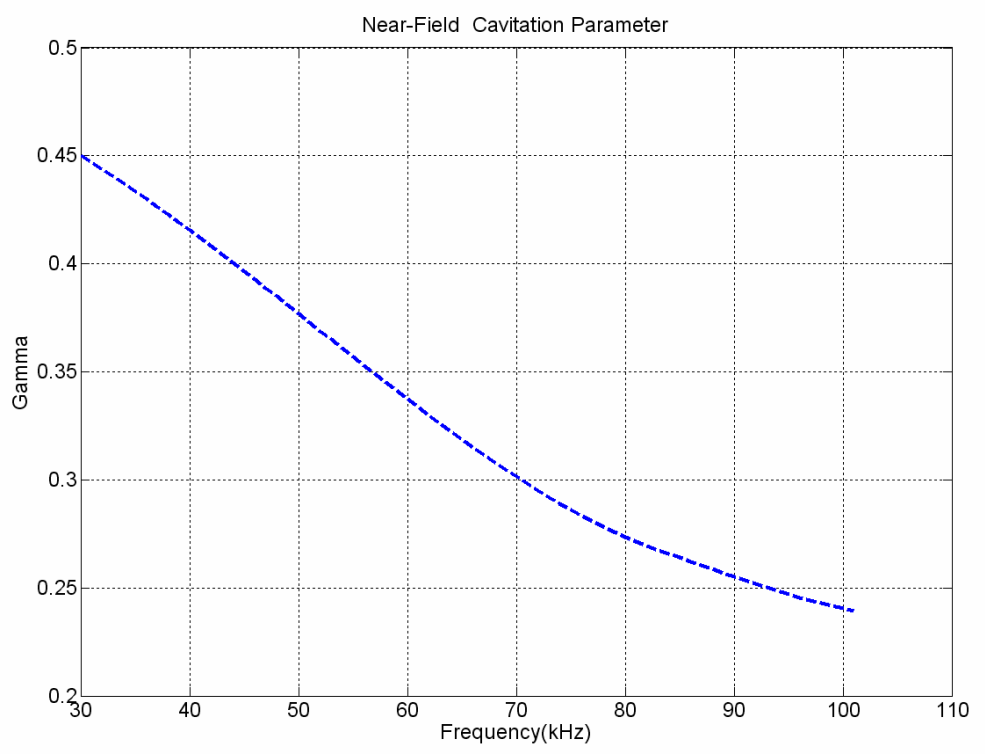

Figure 32. Near-Field cavitation parameter 


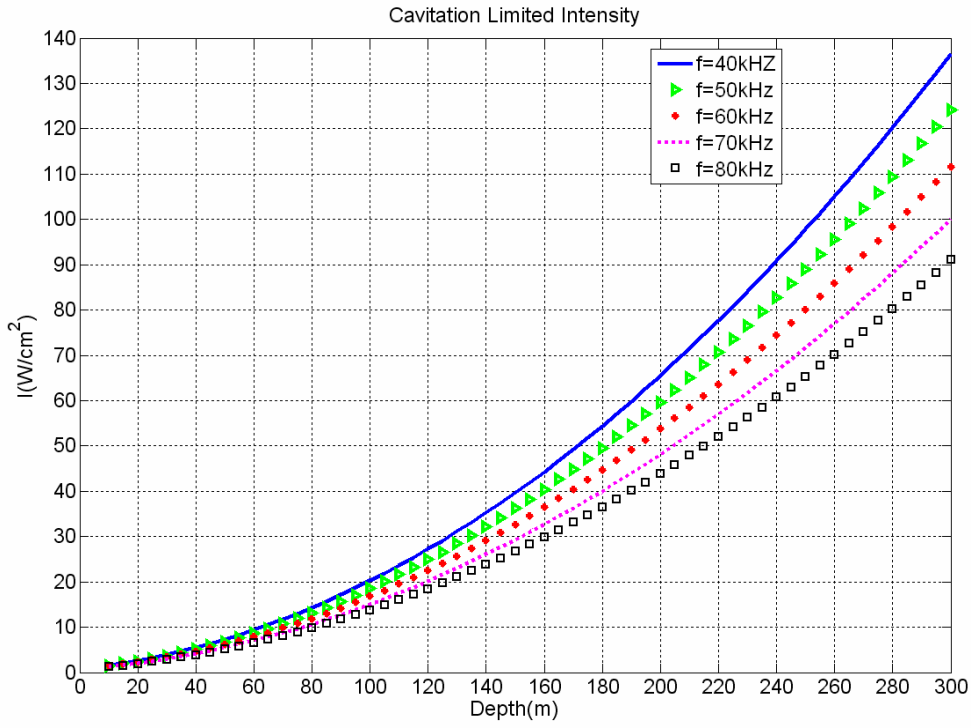

Figure 33. Cavitation limited intensity for different frequencies

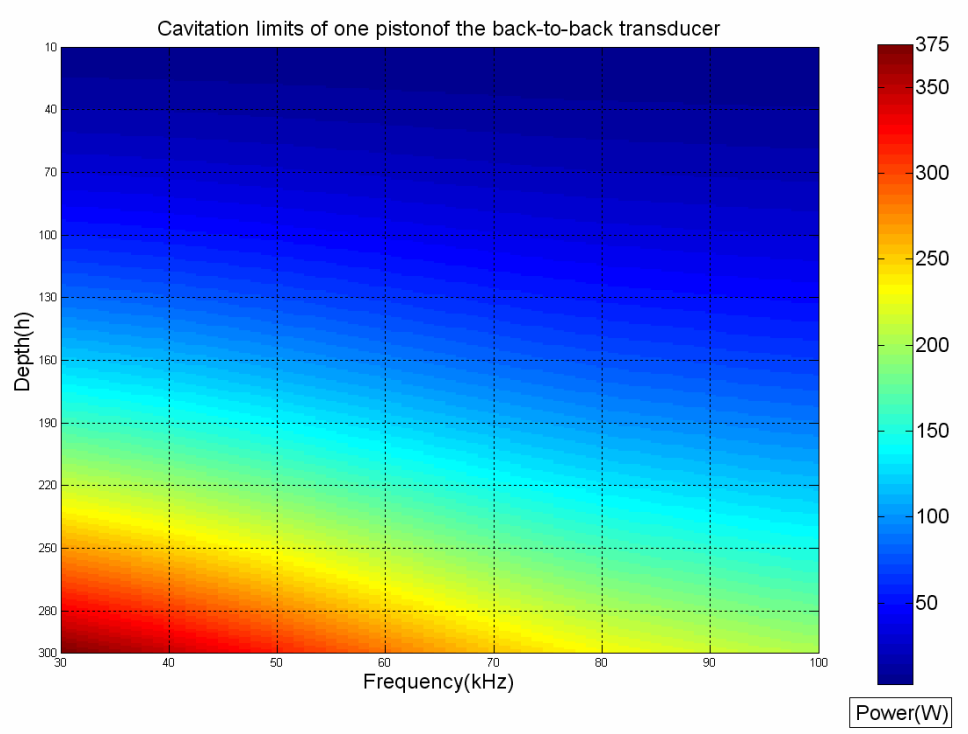

Figure 34. Cavitation limited acoustic power from one piston with respect to frequency and depth 
Note from Fig. 34 that, the back-to-back transducer can be driven with full power, approximately $125 \mathrm{~W}$ from each piston, at depths more than $150 \mathrm{~m}$ at 40 $\mathrm{kHz}$. At $78 \mathrm{kHz}$, the transducer requires more than $200 \mathrm{~m}$ depth in order to deliver full power without cavitation. Therefore, we conclude that cavitation limit is of paramount importance for high power transducers and transducers must be driven carefully such that cavitation does not occur.

\subsection{Admittance Measurement of the Back-to-Back Transducer}

We construct the back-to-back transducer as shown in Fig. 35. Note that instead of rigid baffle, plastic mount is used for the measurement of admittance to ease mounting and demounting of the transducer before finalizing it. Measurement of admittance is conducted in the water tank, given in Fig. 36, whose dimensions are $2 \mathrm{mX} 2 \mathrm{~m}$ and $1.5 \mathrm{~m}$ deep. The tank is made of steel; therefore, measurement of admittance by continuous wave would not be appropriate since there will be high reflections from the walls. Instead, we constitute the measurement setup as given in Fig. 37 and measure the admittance by burst technique. Using the Agilent VEE, we write a program that controls Tektronix 3052B Oscilloscope and Agilent 33120A Function Generator via GPIB interface [23]. User interface of written program is designed, shown in Fig. 38, such that input voltage, frequency range, frequency step and number of cycles are adjustable.

For each frequency, we apply 20 cycles of burst and measure the current, voltage and phase between the voltage and current and calculate the conductance and susceptance for that frequency. Between each frequency step, there is a two second waiting time for the reflections to fade out. Number of cycles should be chosen carefully so that transducer is in steady state for 
sufficient cycles to carry out the measurement. If the measurement is performed in the transient region, results would be erroneous.

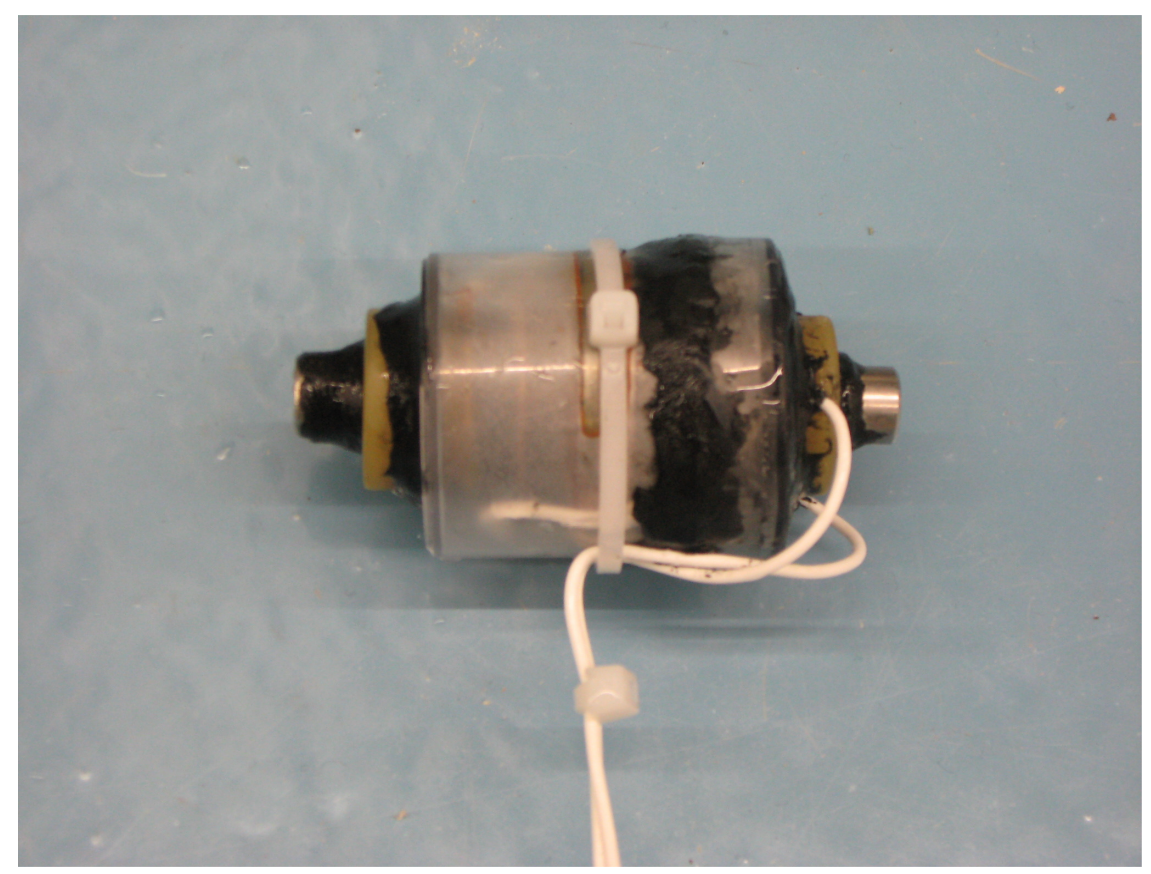

Figure 35. Constructed back-to-back transducer with plastic baffle.

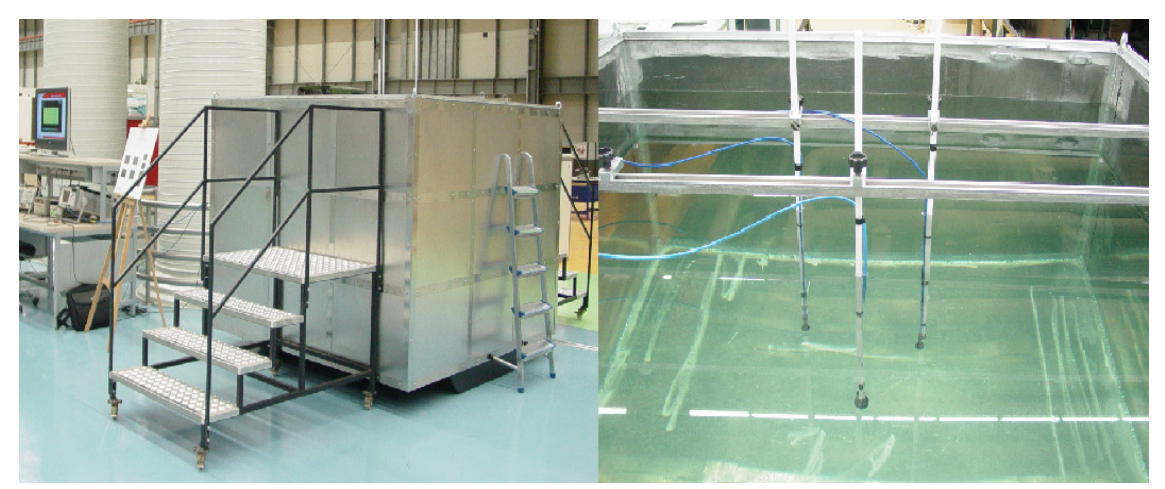

Figure 36. Water tank with dimensions $2 \mathrm{mX} 2 \mathrm{~m}$ and $1.5 \mathrm{~m}$ deep. 


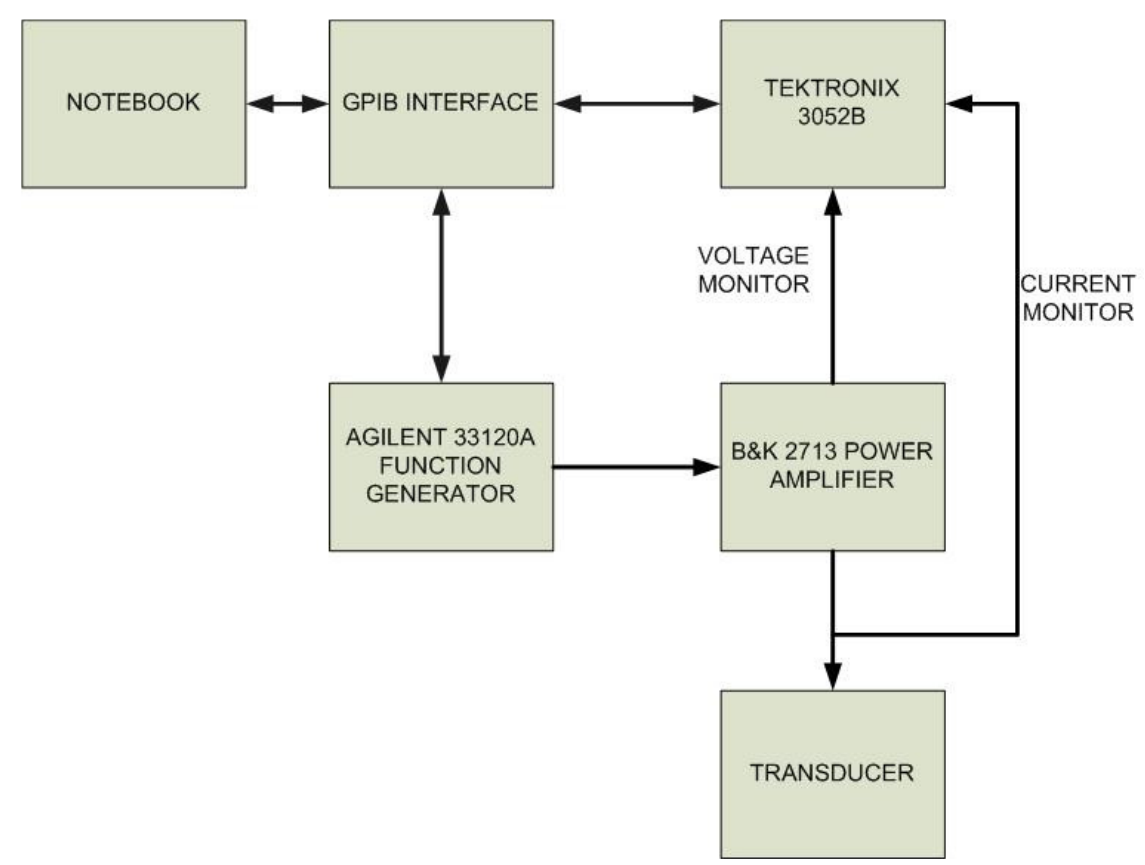

Figure 37. Block diagram of the setup for admittance measurement

Conductance-susceptance plot from the measured data is plotted as shown in Fig. 39. Fig. 40 and Fig. 41 show the comparison of the conductance and susceptance, respectively, obtained from FEM analysis and measurement data. Note that conductance-susceptance values agree well with the theoretical results and $\% 60$ bandwidth is achieved around $42 \mathrm{kHz}-78 \mathrm{kHz}$ with a resonance frequency of $60 \mathrm{kHz}$. The effect of lowest radial resonance of the structure near $100 \mathrm{kHz}$ is also visible in the measured admittance plot. 


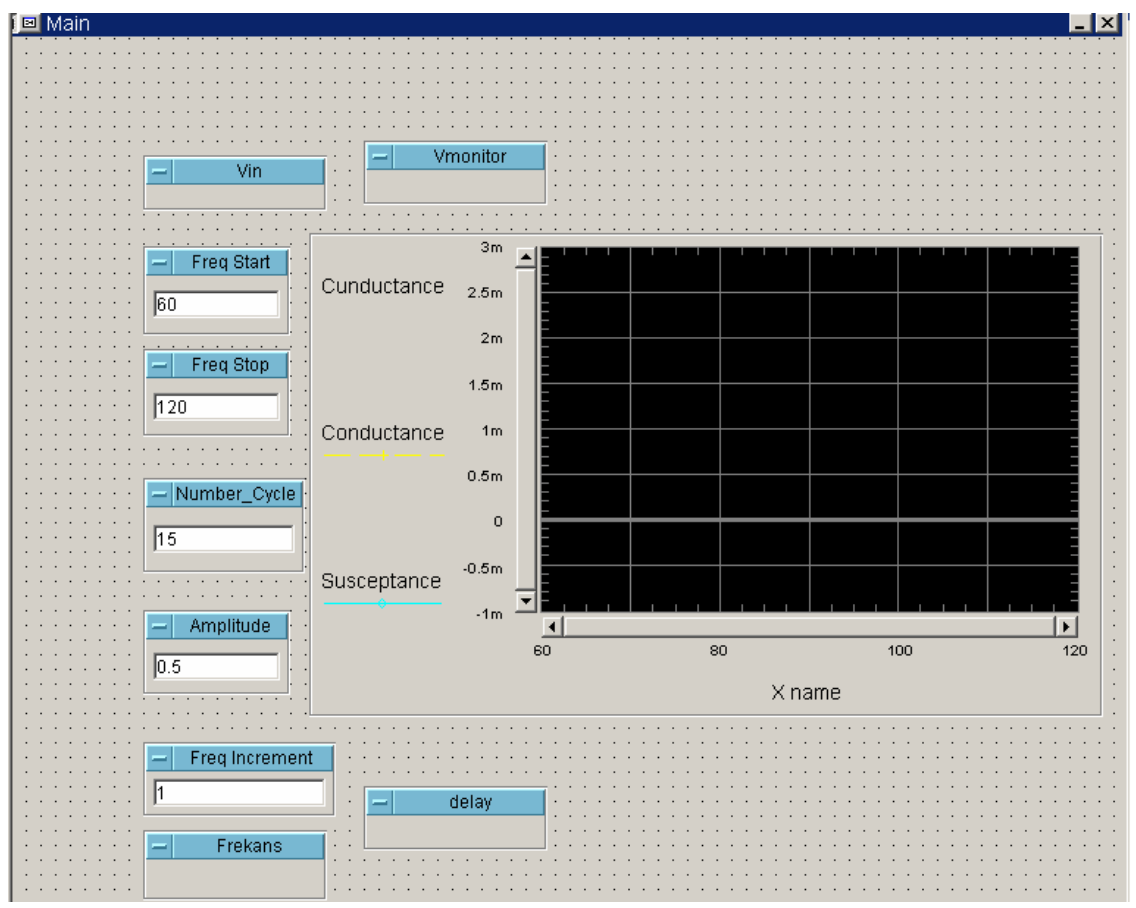

Figure 38. Control interface for the admittance measurement

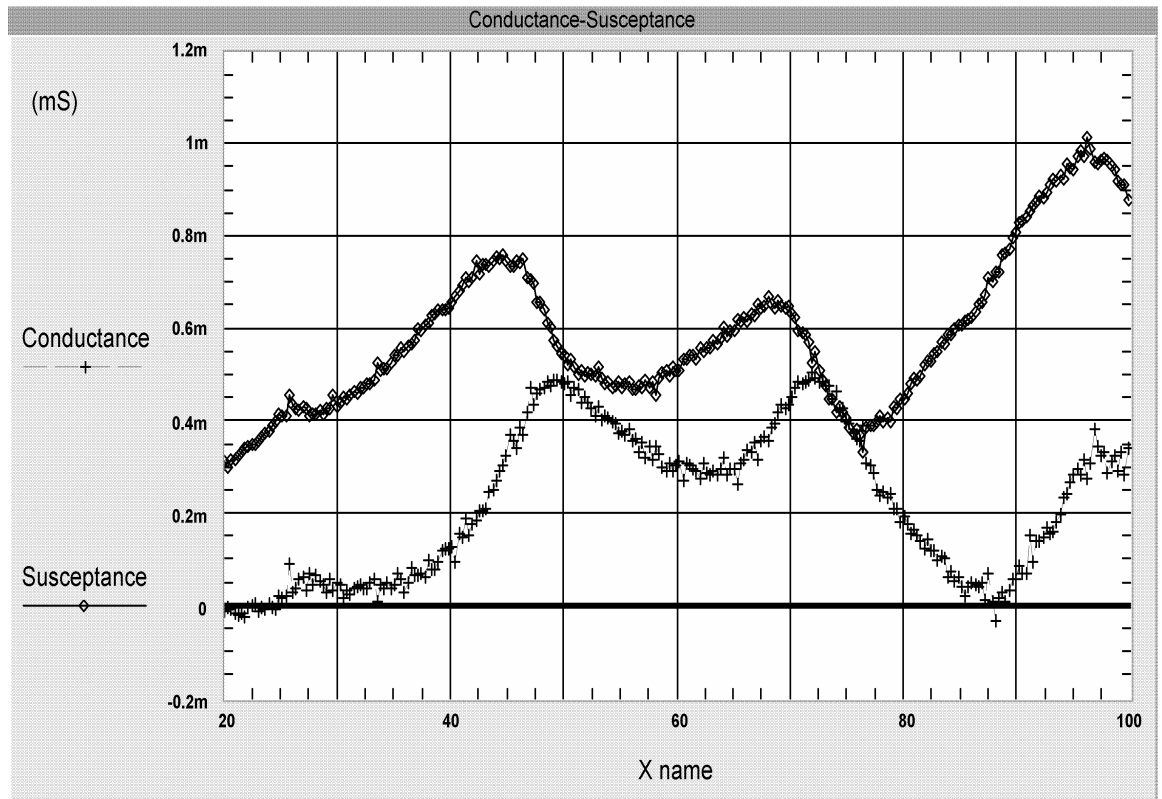

Figure 39. Conductance-Susceptance obtained from measurement. 


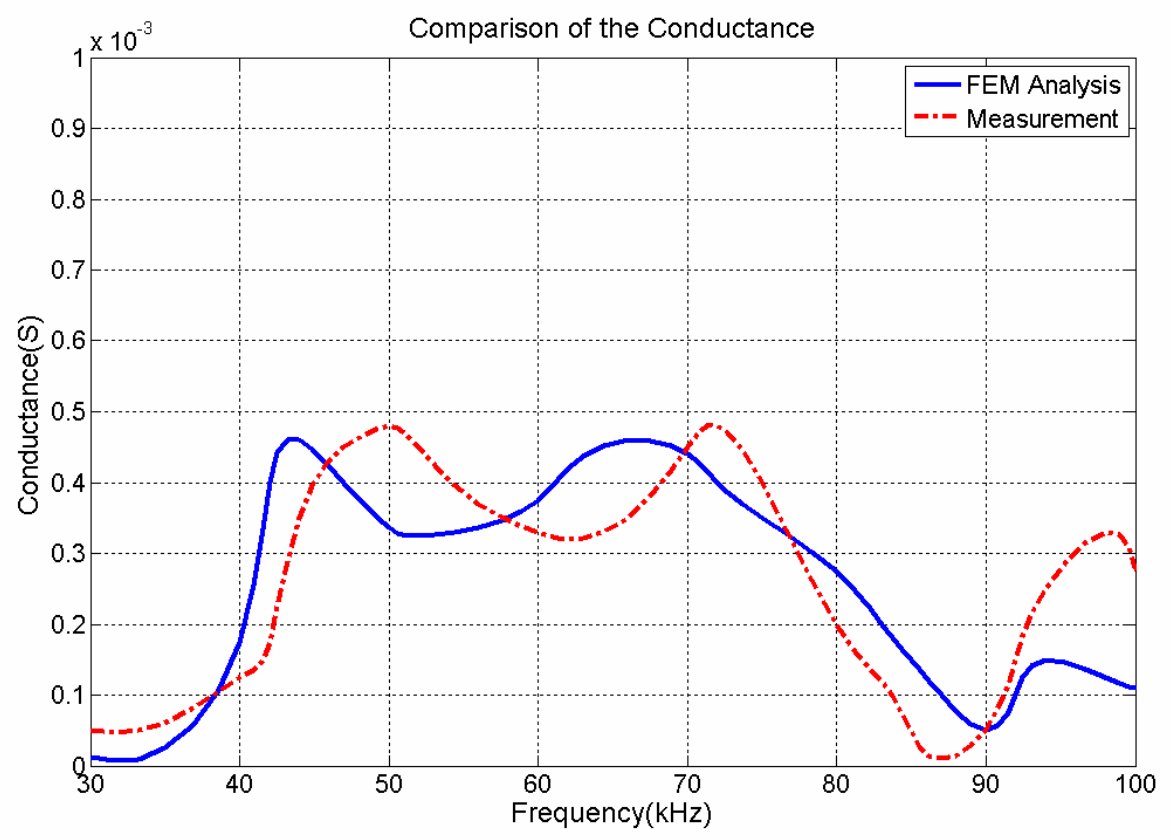

Figure 40. Comparison of the conductance from FEM analysis and measured data.

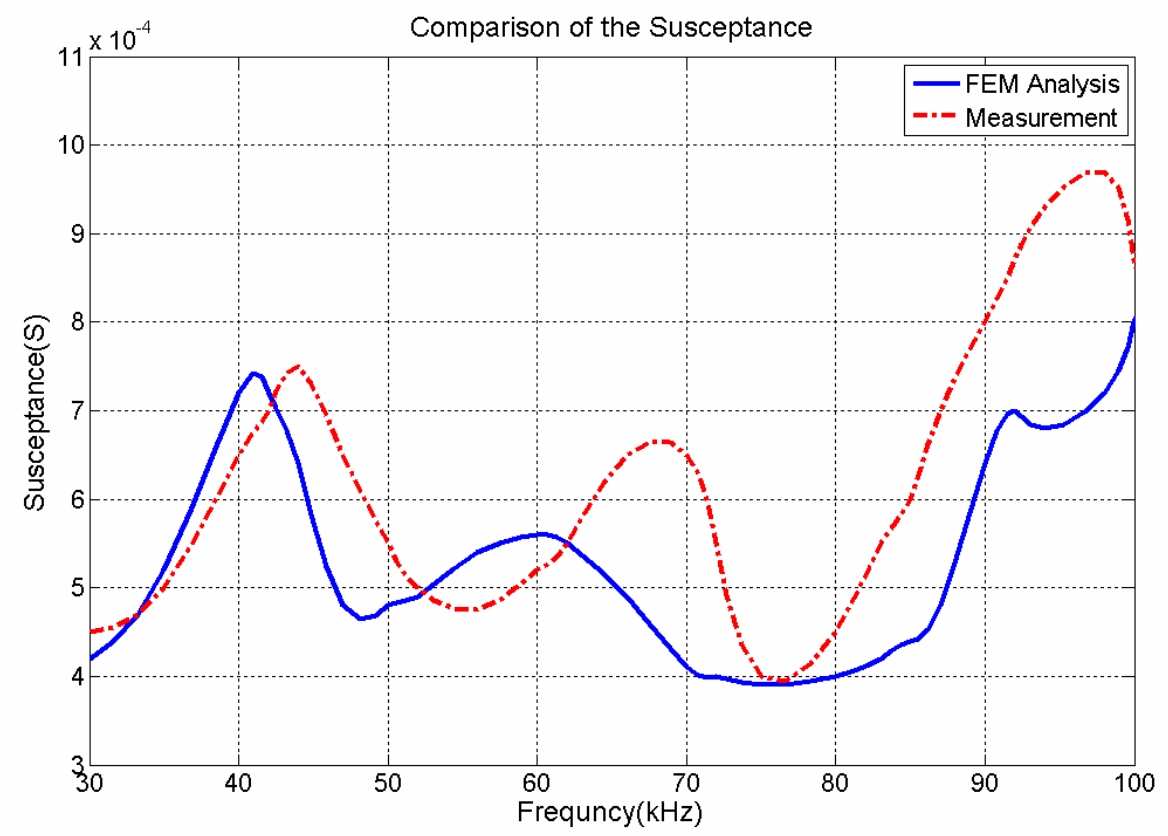

Figure 41. Comparison of the susceptance from FEM analysis and measured data. 


\section{Chapter 5}

\section{Conclusions}

In this thesis paper, we show the design of a half wavelength bi-directional sandwich transducer using two quarter wavelength elements stacked in a backto-back configuration. Overall transducer operates at frequency range $42 \mathrm{kHz}$ $78 \mathrm{kHz}$ and has a beamwidth of $60^{\circ}$ in each half space.

We analyze the difference between infinite and finite baffle and show that infinite baffle assumption would not be appropriate for practical purposes since it neglects all the reflections from the edges of the transducer.

A recursive method for the calculation of power series coefficients of a disc in a finite baffle given by Mellow is derived. Then, a new geometry is proposed such that when the two back-to-back transducers are placed spatially symmetric around the origin a nearly omnidirectional beam pattern can be achievable. We analyze the far field radiation pattern of this geometry for various combinations of piston and baffle radii, $a$ and $b$, and transducer length in order to determine the best $\mathrm{a}$ and $\mathrm{b}$ combination for widest beamwidth in the operating frequency band. With $\mathrm{a}=9 \mathrm{~mm}, r=25 \mathrm{~mm}$ and $b=2 a$ an omnidirectional beam pattern is achieved in the lower frequencies, while at the higher end of the frequency band two dips, within $8 \mathrm{~dB}$, take place in each quadrant.

The back-to-back transducer is designed using equivalent circuit model and dimensions of the layers are tuned using FEM. FEM model provides a means of tuning the design before production since it takes into account sound speed variations and radial and shear mode vibrations. Although equivalent circuit model slightly differs from the FEM model, especially in terms of overall 
frequency band, it provides good insight into the design of the transducer. In fact, if the exact value of sound speeds in the layers are determined; closer results to the FEM would be expected.

In high power transducers, power may be limited by thermal characteristics of the transducer. Therefore, we analyze the back-to-back transducer from thermal point of view and investigate the effects of coating and filling materials on heating characteristics of the back-to-back transducer. Proper choice of the coating and filling materials that have high thermal conductivity prevents maximum temperature in ceramics to rise to critical values and thus enable high power operation.

The most important problem that limits the power of sandwich transducers is cavitation. Although transducers can be driven with full power in deep-water, more than $200 \mathrm{~m}$ in the frequency band of $42 \mathrm{kHz}-78 \mathrm{kHz}$, power capability may drop down to few watts per $\mathrm{cm}^{2}$ in shallow water.

Finally, admittance measurement shows that, experimental results are very close to the ones obtained in FEM. Since the material properties of the matching layer is not known exactly, experimental results deviates from the FEM results to some extent. In fact, we would expect to obtain nearly the same results with FEM if the exact material properties are provided to the ANSYS.

As a future work, geometry shown in Fig 5 could be constructed with two back-to-back transducers. Radiation pattern and thermal performance of the overall transducer could be measured. 


\section{Appendix I}

\section{Mathematical Formulation of Piezoelectric Effect}

Stress, $T$, Strain, $S$, electric field, $E$ and electric displacement, $D$, are related to each other by following relationships;

$$
\begin{aligned}
& S=s^{E} T+d^{t} E \\
& D=d T+\varepsilon^{T} E
\end{aligned}
$$

in which, $S$ and $T$ are $1 \times 6$ column matrices, $E$ and $D$ are $1 \times 3$ column matrices, $d$ is a 3x6 matrix of piezoelectric coefficients, $s^{E}$ is a $6 \times 6$ matrix of compliance coefficients and $\varepsilon^{T}$ is $3 \times 3$ matrix of permittivity coefficients. Note that $d^{t}$ is the transpose of $d$. Superscripts corresponds to the variable that is held constant. Combining Eq. I.1 and Eq. I.2 yields;

$$
\left[\begin{array}{l}
S \\
D
\end{array}\right]=\left[\begin{array}{ll}
s^{E} & d^{t} \\
d & \varepsilon^{T}
\end{array}\right]\left[\begin{array}{l}
T \\
E
\end{array}\right]
$$

Many of the coefficients are zero in the equation above and some of them are related to each other. Then, Eq. I.3 can be written in extended form as follows; 
$\left[\begin{array}{l}S_{1} \\ S_{2} \\ S_{3} \\ S_{4} \\ S_{5} \\ S_{6} \\ D_{1} \\ D_{2} \\ D_{3}\end{array}\right]=\left[\begin{array}{lllllllll}s_{11}^{E} & s_{12}^{E} & s_{13}^{E} & 0 & 0 & 0 & 0 & 0 & d_{31} \\ s_{12}^{E} & s_{11}^{E} & s_{13}^{E} & 0 & 0 & 0 & 0 & 0 & d_{31} \\ s_{13}^{E} & s_{13}^{E} & s_{33}^{E} & 0 & 0 & 0 & 0 & 0 & d_{33} \\ 0 & 0 & 0 & s_{44}^{E} & 0 & 0 & 0 & d_{15} & 0 \\ 0 & 0 & 0 & 0 & s_{44}^{E} & 0 & d_{15} & 0 & 0 \\ 0 & 0 & 0 & 0 & 0 & s_{66}^{E} & 0 & 0 & 0 \\ 0 & 0 & 0 & 0 & d_{15} & 0 & \varepsilon_{11}^{T} & 0 & 0 \\ 0 & 0 & 0 & d_{15} & 0 & 0 & 0 & \varepsilon_{11}^{T} & 0 \\ d_{31} & d_{31} & d_{15} & 0 & 0 & 0 & 0 & 0 & \varepsilon_{33}^{T}\end{array}\right]\left[\begin{array}{c}T_{1} \\ T_{2} \\ T_{3} \\ T_{4} \\ T_{5} \\ T_{6} \\ E_{1} \\ E_{2} \\ E_{3}\end{array}\right]$

where subscripts 4,5 and 6 corresponds to shear stresses and strains. 


\section{Properties of PZT Ceramics}

Table 2 shows the basic properties of PZT-2, PZT-4, PZT-5A, PZT-5H and PZT-8 types ceramics.

\begin{tabular}{|c|c|c|c|c|c|}
\hline$\varepsilon_{33}^{T}$ & 450 & 1300 & 1700 & 3400 & 1000 \\
\hline$\varepsilon_{33}^{S}$ & 260 & 635 & 830 & 1470 & 600 \\
\hline$k_{33}$ & 0.626 & 0.7 & 0.705 & 0.752 & 0.64 \\
\hline $\begin{array}{c}\text { tan } \delta \\
Q_{m}\end{array}$ & 0.005 & 0.004 & 0.02 & 0.02 & 0.004 \\
\hline $\begin{array}{c}\text { AC field for } \\
\text { tan } \delta=0.04 \\
\text { at 25ㄷ }\end{array}$ & 1.8 & 3.9 & 0.45 & 0.3 & 10 \\
\hline $\begin{array}{c}\text { AC field for } \\
\text { tan } \delta=0.04 \\
\text { at } 100^{\circ} \mathrm{C} \\
\text { (kV/cm) }\end{array}$ & 1.6 & 3.3 & 0.45 & 0.2 & 1000 \\
\hline $\begin{array}{c}\text { Maximum rated } \\
\text { compressive } \\
\text { stress } 25^{\circ} \mathrm{C} \\
\text { (psi) }\end{array}$ & - & 12000 & 3000 & 2500 & - \\
\hline $\begin{array}{c}\text { AC depoling } \\
\text { field }\end{array}$ & $>10$ & $>10$ & 7 & & \\
\hline
\end{tabular}

Table 2. Properties of common PZT types.

Units and description of properties are; 
$\varepsilon_{33}^{T} \quad:$ Free relative dielectric constant

$\varepsilon_{33}^{S} \quad:$ Clamped relative dielectric constant

$k_{33} \quad$ : Longitudinal coupling factor

tan $\delta \quad$ : Dissipation factor at $1 \mathrm{kHz}$ and low field

$Q_{m} \quad$ : Mechanical quality factor.

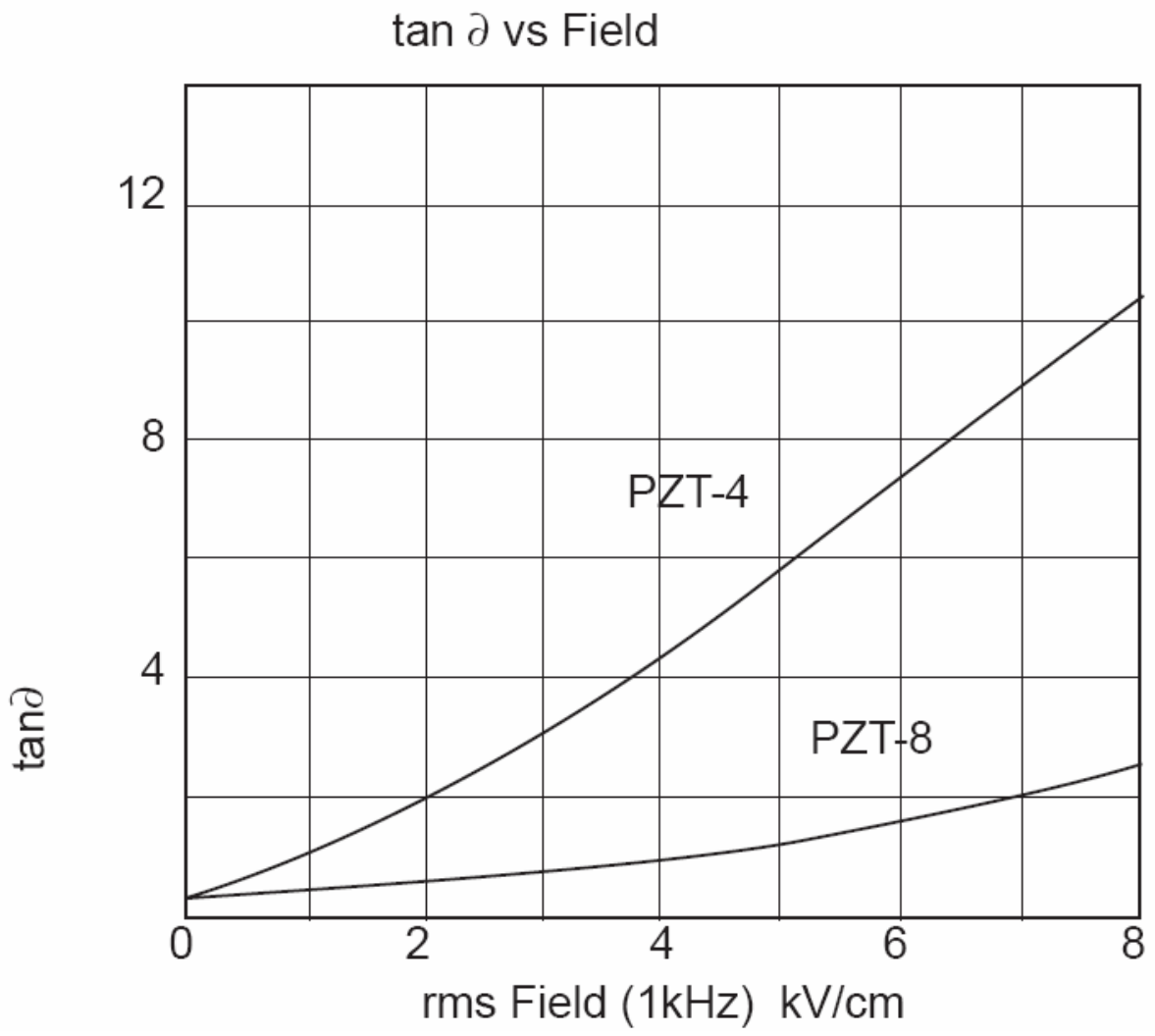

Figure 42. Comparison of dielectric tangent loss for PZT-4 and PZT-8 [7]

\section{Piezoelectric Coefficient Matrices for Thickness Mode Transducer}

Piezoelectric coefficient matrices of a PZT-4 ring oriented such that its polarization direction is aligned with the $+\mathrm{Y}$ axis is as follows [24]:

PZT4 Dielectric Matrix $\left[\varepsilon_{r}\right]$ : 


$$
\left[\begin{array}{lll}
728.5 & 0 & 0 \\
0 & 634.7 & 0 \\
0 & 0 & 728.5
\end{array}\right]
$$

PZT4 Piezoelectric Matrix [e] $C / \mathrm{m}^{2}$

$$
\left[\begin{array}{lll}
0 & -5.2 & 0 \\
0 & 15.1 & 0 \\
0 & -5.2 & 0 \\
12.7 & 0 & 0 \\
0 & 0 & 12.7 \\
0 & 0 & 0
\end{array}\right]
$$

PZT4 Stiffness matrix [c] x GPa

$$
\left[\begin{array}{llllll}
139 & 74.3 & 77.8 & 0 & 0 & 0 \\
& 115 & 74.3 & 0 & 0 & 0 \\
& & 139 & 0 & 0 & 0 \\
& & & 25.6 & 0 & 0 \\
& & & & 25.6 & 0 \\
& & & & & 30.6
\end{array}\right]
$$

Piezoelectric coefficient matrices of a PZT-4 ring oriented such that its polarization direction is aligned with the $-\mathrm{Y}$ axis is the same as above except for the piezoelectric matrix which is given by:

$$
\left[\begin{array}{lll}
0 & 5.2 & 0 \\
0 & -15.1 & 0 \\
0 & 5.2 & 0 \\
12.7 & 0 & 0 \\
0 & 0 & 12.7 \\
0 & 0 & 0
\end{array}\right]
$$




\section{Appendix II}

\section{Calculation of Power Series Coefficients of a Disc}

Bouwkamp and Streng functions are defined respectively as;

$$
\begin{gathered}
{ }_{m} B_{q}(k b)=\sqrt{\pi} \sum_{r=0}^{M} \frac{(-1)^{q+r} \Gamma(m+5 / 2) \Gamma(q+r+1)}{r !(q !)^{2} \Gamma(r+m+5 / 2) \Gamma(q+r+5 / 2)} x\left(\frac{k b}{2}\right)^{2(q+r)+3} \\
{ }_{m} S_{q}(k b)=\sqrt{\pi} \sum_{r=0}^{M} \frac{(-1)^{q+r+m} \Gamma(m+5 / 2) \Gamma(q+r-m-1 / 2)}{r !(q !)^{2} \Gamma(r-m-1 / 2) \Gamma(q+r-m+1)} x\left(\frac{k b}{2}\right)^{2(q+r-m)} \\
\Phi_{q}=\frac{a}{b} \sum_{n=1}^{N} \frac{(-1)^{q} J_{1}\left(j_{0 n} a / b\right)}{(q !)^{2} J_{1}^{2}\left(j_{0 n}\right)} x\left(\frac{j_{0 n}}{2}\right)^{2 q-1}
\end{gathered}
$$

such that

$$
\sum\left({ }_{m} B_{q}(k b)-i_{m} S_{q}(k b)\right) \tau_{m}=-\Phi_{q}
$$

In Eq II.4 $\tau_{m}$ corresponds to power series coefficients. $\Phi, a, b, J$ and $\Gamma$ are, Bessel series, piston radius, baffle radius, Bessel and Gamma functions, respectively. Combining the results of a radiation form a disc in a finite open baffle with that of an infinite baffle gives the directivity function of a disc in a finite closed circular baffle as;

$$
D(\theta)=\frac{2 J_{1}(k a \sin \theta)}{k a \sin \theta}-k b\left(\frac{b}{a}\right)^{2} \cos \theta \sum_{m=0}^{M} \tau_{m} \Gamma(m+5 / 2)\left(\frac{2}{k b \sin \theta}\right)^{m+3 / 2} J_{m+3 / 2}(k b \sin \theta)
$$

First term is the directivity function of a disc in an infinite baffle and second term comes from a disc in a finite open baffle.

Similar approach can be applied to radiation impedance such that real and imaginary part of normalized impedance can be written as;

$$
R_{R}=\frac{1}{2}\left[1-\frac{J_{1}(2 k a)}{k a}-k b\left(\frac{b}{a}\right)^{2} \sum_{m=0}^{M} \Re\left(\tau_{m}\right)\left(1-\left(1-\frac{a^{2}}{b^{2}}\right)^{m+3 / 2}\right)\right]
$$




$$
X_{R}=\frac{1}{2}\left[\frac{H_{1}(2 k a)}{k a}-k b\left(\frac{b}{a}\right)^{2} \sum_{m=0}^{M} \mathfrak{I}\left(\tau_{m}\right)\left(1-\left(1-\frac{a^{2}}{b^{2}}\right)^{m+3 / 2}\right)\right]
$$

where $H$ is the Struve function. 


\section{BIBLIOGRAPHY}

[1] T. Mellow, L. Kärkkäinen, On the sound field of an oscillating disk in a finite open and closed circular baffle. Joint Acoustical Society of America, 118(3), Pt.1, 2005

[2] William S. Burdic, Underwater Acoustic System Analysis. Prentice-Hall, 1990

[3] Charles H. Sherman and John L. Butler, Transducers and Arrays for Underwater Sound. Springer, 2007

[4] William A. Kuperman and Philippe Roux, Introduction to Underwater Acoustics. Notes for a short Course, 2006

[5] A. Arnau, Piezoelectric Transducers and Applications. Springer, 2003

[6] Piezoelectric Ceramics, http://www.channelindustries.com/catalog.htm

[7] Properties of Piezoelectric Ceramics, www.morgan-electroceramics.com

[8] W. P. Mason, Electromechanical Transducers and Wave Filters, D. Van Nostrand Company, 1942

[9] G. Kossoff, The Effects of Backing and Matching on the Performance of Piezoelectric Ceramic Transducers, IEEE Trans. On Sonics and Ultrasonics SU-13, pp. 20 - 30, 1996 
[10] L. V. King, On the Acoustic Radiation Field of the Piezoelectric Oscillator and the Effect of Viscosity on the Transmission. Can. J. Res. 11, pp. 135-146, 1934.

[11] T. Nimura and Y. Watanabe, Effect of a Finite Circular Baffle Board on Acoustic Radiation. J. Acoust. Soc. Am. 25(1), pp.76-80, 1952

[12] H. Levine and J. Schwinger, On the Radiation of Sound from an Unflanged Circular Pipe. Phys. Rev. 73(4), pp. 383-406, 1948

[13] M. Abramowitz, I.A. Stegun. Handbook of Mathematical Functions. Dover, 1972.

[14] ANSYS, Multiphysics. Ansys Inc., 2007

[15] D. Stansfield, Underwater Electroacoustic Transducers. Bath, UK: Bath Univ. Press, 1990.

[16] MathWorks, "MATLAB reference guide (Version 7.5 R2007b)," The MathWorks Inc, Natick, MA, 2007.

[17] ANSYS, Release 10.0 Documentation for ANSYS. ANSYS Inc., 2007

[18] Stephen C. Butler, John B. Blottman and Robert E. Montgomery, A Thermal Analysis of High-Drive Ring Transducer Elements. NUWCNPT Technical Report 11,467, 2005 
[19] FLUX2D, Electromagnetic and Thermal Analysis 2-D Finite Element Program. Magsoft Corporation, Troy, NY.

[20] LOCTITE, Loctite 3873 Technical Data Sheet, 2004

[21] Robert J. Urick, Principles of Underwater Sound. McGraw-Hill Book Company, 1983.

[22] V.A. Akulichev and V.I. Il'ichev, Acoustic Cavitation Thresholds of Sea Water in Different Regions of the World Ocean. Acoustical Physics, Vol. 51, No.2, pp. 128-138, 2005

[23] VEE, Pro 7.5, Agilent Technologies, 2007

[24] ANSYS, Piezoelectric Rectangular Strip under Pure Bending Load, VM231 